\title{
Intensive Care Unit Acquired Weakness (ICU-AW): a brief and practical review
}

Daniel Agustin Godoy 1,2, Leonardo Vaz de Mello ${ }^{3,4}$, Luca Masotti ${ }^{5}$, Mario Di Napoli ${ }^{6}$

Intensive Care Unit, Hospital San Juan Bautista, Catamarca, Argentina

Neurointensive Care Unit, Sanatorio Pasteur, Catamarca, Argentina

Neurology Service, Santa Casa de São João del Rey, Minas Gerais, Brazil

Hospital Nossa Senhora das Merces, Minas Gerais, Brazil

Internal Medicine, Santa Maria Nuova Hospital Florence, Italy

Neurological Service, San Camillo de' Lellis General Hospital, Rieti, Italy

\section{Abstract}

Intensive care unit-acquired weakness (ICU-AW) is an increasingly complication of survivors of critical illness. It should be suspected in the presence of a patient with a flaccid tetraparesis or tetraplegia with hyporeflexia or absent deep tendon reflexes and difficult to weaning from mechanical ventilation in the absence of different diagnoses. Important risk factors are age, sepsis, illness duration and severity, some drugs (neuromuscular blockers, steroids). Electrophysiological studies have shown an axonal damage of involved peripheral nerves (critical illness polyneuropathy). However, muscle can also be primitively affected (critical illness myopathy) leading to ICU-AW with inconstant myopathic damage patterns in electromyographic studies. Mixed forms can are present (critical illness polyneuromyopathy. Although the pathophysiology remains obscure, the hypothesis of an acquired channelopathy is substantial. Electroneuromyography is crucial for diagnosis. Muscular and nerve biopsies are necessary for diagnosis confirmation. Aggressive treatment of baseline disease, prevention, through avoiding or minimizing precipitating factors, strict glycemic control, and early rehabilitation combining mobilization with physiotherapy and muscle electrical muscle stimulation, are the keys to improving recovery of the affected individuals. This narrative review highlights the current literature regarding the etiology and diagnosis of ICU-AW.

\section{Keywords}

Intensive Care Unit Acquired Weakness (ICU-AW); Electrodiagnosis; Critical illness 


\section{Introduction}

Sir W. Osler did the first description of weakness in critical illness patients in the pre-antibiotic era [1], when he described a rapid loss of flesh in a person with prolonged sepsis and multiorgan failure. At the end of '70s and first ' 80 s, physicians and neurologists pointed their attention in some patients that developed weakness of the limbs, arms or both with absent or hypoactive deep tendon reflexes, atrophy or loss of muscle fibers, fasciculations and frequently tetraparesis or tetraplegia after recovery from severe sepsis or other devastating inflammatory states [2-8]. These observations were more frequent as survival rates among patients in the intensive care unit (ICU) increased, and ICU-acquired weakness (ICU-AW) increased relevance for care providers outside the ICUs. Since then, numerous case series and observational studies of ICU-AW have led to an explosion in the number of terms used to describe this syndrome (critical illness polyneuropathy (CIP), critical illness myopathy (CIM), CRIMYNE, etc.) [9-11]. As a result, only recently a new scheme to diagnose and classify ICU-AW has been proposed to ensure consistent identification of ICU-AW patients [12]. Motor weakness may be related to (1) pre-existing neuromuscular disorder leading to ICU admission, (2) new-onset or previously undiagnosed neurological disorder, or (3) complications of non-neuromuscular critical illness. Neuromuscular syndromes related to ICU treatment consist of CIP, CIM, and prolonged neuromuscular blockade (PNB). They are recognized as a frequent cause of newly acquired weakness in ICU patients. Using this diagnostic definition, ICU-AW can be recognized more quickly permitting more uniform reporting of affected patients by intensivists.

By definition, ICU-AW is a tetraparesis or tetraplegia with hyporeflexia, or absent deep tendon reflexes muscle wasting, and difficulty weaning from the ventilator. Evaluation of these patients is based on neurological examination, detailed electrophysiological investigation, serum creatine kinase (CK) level, knowledge of clinical setting and predisposing factors, other laboratory studies as needed, and histological examination of muscle biopsy. Without electrophysiological studies, it is impossible to define and to characterize ICU-AW, phrenic nerve conduction, diaphragm electromyography, blink reflex, and the technique of direct muscle stimulation (DMS) could be employed together with conventional nerve conduction studies and needle electromyography. Today, ICU-AW should be suspected in any patient who develops generalized muscle weakness or impossibility to wean from the mechanical ventilator after recovering from a severe critical illness [4-8]. Primary differential diagnoses of critical illness related paralysis are incidental Guillain-Barré syndrome (GBS) and unmasked myasthenia gravis. Less frequent diagnosis to consider are atypical presentation of amyotrophic lateral sclerosis (ALS), polymyositis or other myopathies, and precipitation of porphyria or rhabdomyolysis due to drugs used in the ICU. Recently a poliomyelitis-like flaccid paralysis due to West Nile virus infection was reported [13]. A subgroup of patients with myasthenia gravis with muscle-specific tyrosine kinase antibody is noted to present as respiratory crisis [14]. Although no specific treatment exists for ICU-AW, understanding its etiology, pathophysiology, and risk factors may be significant for the prevention. Because the diagnosis and the management of ICU-AW can be sometimes difficult, this narrative review aims to help in organizing a practical approach to the diagnosis and management of ICU-AW patients.

\section{Incidence}

The real incidence of ICU-AW is unclear and varies between studies. This variability reflects different populations, risk factors, definitions of this syndrome, absence of diagnostic criteria widely validated and the difficulty to differentiate all clinical forms adequately [6-9]. It ranges between $7 \%$ in patients undergoing liver transplantation [15] to $33 \%$ in patients admitted to the intensive care unit with status asthmaticus [16]. Recent reviews report an incidence of 30 to $46 \%$, mainly, secondary to sepsis and multi-organ dysfunction syndrome (MODS) $[10,17]$. The incidence is also higher $(30-60 \%)$ in patients 
with acute respiratory distress syndrome (ARDS), especially in patients with long-term (> 1 week) duration of mechanical ventilation $[7,18,19]$. Seventy percent of patients with sepsis may suffer from CIP [6]. In children, the risk is less well defined as there are no prospective clinical and electrophysiologic studies.

\section{Short- and long-term outcomes}

ICU-AW appears to influence short and long-term measures of outcome. However, the risk of selection bias in published studies is high due to the combination of varied definitions of neuromuscular impairment and the use of selected cohorts. When the combination of severe sepsis, septic shock, and coma are present, mortality is near to $100 \%[7,8,20,21]$. However, there is not yet a definite cause-and-effect relationship. No conclusive evidence exists to refute the possibility that poor outcomes and weakness may only reflect the type and severity of the patient's underlying pathology [22]. Furthermore, muscle wasting and weakness are common among ICU-AW survivors in long-term follow-up studies [23]. Latronico and colleagues evaluated 36 studies ( $n=263$ patients) reporting long-term outcomes in heterogeneous ICU-AW populations [24], indicating a complete functional recovery (defined as breathing spontaneously and walking independently) in $68 \%$ of cases. A severe disability (defined as quadriparesis, quadriplegia, or paraplegia) was present in $28 \%$ of cases. Persisting milder disabilities (reduced or absent deep tendon reflexes, stocking and glove sensory loss, muscle atrophy, painful hyperesthesia, and foot drop) are common even in patients with complete functional recovery [25].

\section{Risk factors}

Table I summarizes the known clinical risk factors of ICU-AW. Multiple risk factors have been identified.

\section{Risk factors}

\begin{tabular}{|c|c|}
\hline Advancing age & Bercker et al. [18], De Letter et al. [20] \\
\hline Female gender & De Jonghe et al. [26] \\
\hline Increased severity of illness & de Letter et al. [20], De Jonghe et al. [26], Bednarik et al. [27] \\
\hline Systemic inflammatory response syndrome & Jaber et al. [28], Levine et al. [29] \\
\hline Multiorgan system failure & De Jonghe et al. [26] \\
\hline Sepsis & Garnacho-Montero et al. [30] \\
\hline Hyperglycemia & Van den Berghe et al. [31] \\
\hline Medications & $\begin{array}{l}\text { Latronico et al. [8], Bercker et al. [18], de Letter et al. [20], De Jonghe et } \\
\text { al. [26], Bednarik et al. [27], Garnacho-Montero et al. [30] }\end{array}$ \\
\hline Corticosteriods & De Jonghe et al. [26] \\
\hline Neuromuscular blocking agents & MacFarlane and Rosenthal [31], Leatherman et al. [32] \\
\hline Aminoglycosides & $\begin{array}{l}\text { Latronico et al. [8], Bercker et al. [18] de Letter et al. [20], De Jonghe et al. } \\
\text { [26], Garnacho-Montero et al. [30] }\end{array}$ \\
\hline Parenteral nutrition & Waldhausen et al. [33], Marino et al. [34] \\
\hline Long duration of mechanical ventilation & De Jonghe et al. [26] \\
\hline Catabolic state & Garnacho-Montero et al. [30], Trojaborg et al. [35] \\
\hline Immobility & Levine et al. [36] \\
\hline Combination of any of the above factors & Hund et al. [37] \\
\hline
\end{tabular}

Table I. Intensive Care Unit Acquired Weakness (ICU-AW) risk factors

\section{References}

Table l. Intensive Care Unit Acquired Weakness (ICU-AW) risk factors 
Undoubtedly, important risk factors are age, sepsis, the duration and the severity of illness, as measured by ICU admission Acute Physiology and Chronic Health Evaluation score or Sequential Organ Failure Assessment score, systemic inflammatory response syndrome (SIRS), and MODS [18-22]. The use of neuromuscular blocking agents, vasopressors, corticosteroids, aminoglycosides and opioids, principally fentanyl, were also associated to ICU-AW. Only anecdotal reports link ICU-AW and administration of parenteral nutrition with the speculation that the use of intravenous fat emulsions with high amounts of polyunsaturated fatty acids could cause axonopathy $[33,34]$. Furthermore, additional risk factors include neurological compromise, hyperglycemia, hypoalbuminemia, hyperosmolarity, parenteral nutrition, renal failure with or without replacement therapy, female sex, joint contractures, and muscle wasting from catabolism and physical inactivity also contribute to ICU-AW $[8,10,17,38,39]$. Short-term immobility impairs microvascular function and induces insulin resistance [40], increases production of pro-inflammatory cytokines and reactive oxygen species, resulting in muscle proteolysis and a net loss of muscle protein and subsequent muscle weakness [41]. Prolonged immobility leads to decreased muscle protein synthesis, increased muscle catabolism, and decreased muscle mass, especially in the lower extremities. However, the presence of so many risk factors suggests that several factors act synergistically in the development of ICU-AW.

\section{Clinical Picture: evaluation and diagnostic criteria for ICU-AW}

The classical clinical findings are flaccid tetraparesis, frequently symmetrical with hypo or areflexia (major finding); atrophy and loss of muscle mass (minor finding) [4-8,25]. An initial examination should be performed upon admission to the ICU, with subsequent examinations paired with daily awakenings or when patients show signs of clinical improvement, allowing cooperation with a more comprehensive examination. The diagnosis of ICU-AW should begin with routine physical and neurological examination of a patient that is weak following an episode of critical illness with the use of the Medical Research Council (MRC) scale. The MRC score is a tool that help to graduate the muscle strength of various muscle groups in the upper and lower extremities [36]. It ranges from 0 to 5 , with higher scores indicating greater muscle strength [36]. It has maximal punctuation of 60 . A combined score of 48 points is a cut-off for presumptive diagnosis of ICU-AW [26]. Patients with ICU-AW according to the MRC score should undergo serial evaluations, and if persistent deficits are noted, electrophysiological studies, muscle biopsy, or both are warranted. Unfortunately, the MRC scale has several limitations due to discrimination and a potential ceiling effect, and we need better bedside tools for identifying the presence of ICU-AW.

Furthermore, weakness can also have a broad differential diagnosis. Table II summarizes common diseases that cause weakness in ICU patients.

Onset of ICU-AW may not be easily appreciated. It is often brought to the attention because of flaccidity and wasting of extremities or difficulty in weaning the patient from mechanical ventilation. Standard neurological examination should be adapted to patient clinical condition because patients' cooperation is often difficult to obtain, muscle strength testing may be inadequate and sensory examination not reliable. Acute motor deficits due to central nervous system (CNS), upper motor neuron injury may cause hypotonia and hyporeflexia similar to lower motorneuron lesions, and clinical differentiation between central and peripheral causes becomes difficult. Neuromuscular and CNS involvement may also be coincidental. Three major features usually point toward CNS involvement: asymmetric neurologic signs (hemispheric lesion), altered mental status (diffuse encephalopathy), and cranial nerve palsies (brain stem lesion). Appropriate imaging (computed tomography, magnetic resonance imaging) and electroencephalogram usually provide the diagnosis. Many spinal cord 


\begin{tabular}{|c|c|c|c|}
\hline Localization & Pre-existing & Previously undiagnosed/new-onset & Critical illness related \\
\hline \multirow[t]{3}{*}{ Spinal cord } & Trauma & Acute ischemia & Not described \\
\hline & Infarction & Epidural abscess & \\
\hline & Transverse myelitis & Acute transverse myelitis & \\
\hline \multirow[t]{2}{*}{ Anterior horn cell } & Amyotrophic lateral sclerosis & $\begin{array}{l}\text { Amyotrophic lateral sclerosis } \\
\text { (predominant diaphragm weakness) }\end{array}$ & Hopkins syndrome \\
\hline & $\begin{array}{l}\text { Poliomyelitis } \\
\text { (West Nile virus) }\end{array}$ & West Nile virus poliomyelitis & \\
\hline \multirow[t]{2}{*}{ Peripheral nerve } & Guillain-Barre' syndrome & Incidental Guillain-Barre's syndrome & $\begin{array}{l}\text { Critical illness } \\
\text { polyneuropathy }\end{array}$ \\
\hline & $\begin{array}{l}\text { Chronic inflammatory } \\
\text { demyelinating } \\
\text { polyneuropathy }\end{array}$ & Porphyria, vasculitis, toxic, compressive & \\
\hline \multirow[t]{3}{*}{$\begin{array}{l}\text { Neuromuscular } \\
\text { junction }\end{array}$} & Myasthenia gravis & Unmasked myasthenia gravis & $\begin{array}{l}\text { Prolonged neuromuscular } \\
\text { blockade }\end{array}$ \\
\hline & Lambert-Eaton syndrome & $\begin{array}{l}\text { Atypical myasthenia gravis (predominant } \\
\text { respiratory weakness, muscle-specific } \\
\text { tyrosine kinase antibody) }\end{array}$ & \\
\hline & Botulism & Toxic & \\
\hline \multirow[t]{5}{*}{ Muscle } & Muscular dystrophy & Rhabdomyolysis & Critical illness myopathy \\
\hline & Polymyositis & Toxic myopathies & \\
\hline & Periodic paralysis & Polymyositis & \\
\hline & Metabolic/congenital & Myotonic dystrophy & \\
\hline & Mitochondrial & $\begin{array}{l}\text { Adult-onset acid maltase deficiency } \\
\text { Pyomyositis Hypokalemic } \\
\text { Hypophosphatemic }\end{array}$ & \\
\hline
\end{tabular}

Table II. Diseases and syndromes causing weakness in patients in the ICU: differential diagnosis

lesions, such as acute transverse myelitis, epidural abscess, and spinal cord infarct, may present as causes of ICU-AW. In the presence of flaccid weakness due to spinal shock, upper versus lower motor neuron paralysis cannot be distinguished. Presence of sensory level on trunk (when it is possible to investigate), Babinski sign, flexor spasms, loss of anal reflex, loss of sphincter control, and arms weaker than legs are some useful signs of spinal cord involvement. Magnetic resonance imaging of the spine is the most useful procedure in any suspicion of a spinal cord lesion. The main clinical features of neuromuscular diseases are weakness and wasting of extremities, hypotonia, and hyporeflexia/areflexia, with or without respiratory and/or cranial musculature involvement. The diseases of the anterior horn cell, neuromuscular junction, and muscle produce pure motor syndromes. Most peripheral nerve disorders have sensory and motor findings. Clinical distinction among these categories may be difficult in the ICU setting because of the impossibility in eliciting signs, overlapping features and simultaneous occurrence of more than one syndrome. Some helpful clinical signs are asymmetric weakness and fasciculations (ALS, viral poliomyelitis); paresthesia, sensory deficits, and distal symmetric weakness (peripheral neuropathy); cranial nerve palsies and dysautonomia (GBS); and combination of ptosis and weakness of eye closure (myasthenia gravis, prolonged neuromuscular junction blockade). Given the complexities of ICU-AW, a standard and practical definition is evidently difficult. To date the nosologic scheme by Stevens et al. $[10,12]$ is a reasonable classification. ICU-AW should be applied in cases in which a patient is noted to have clinically detected weakness 


\begin{tabular}{|c|c|c|}
\hline Prodromal conditions & Sepsis and multiple organ failure & Gastrointestinal or respiratory infection \\
\hline \multirow[t]{3}{*}{ Clinical presentation } & $\begin{array}{l}\text { Onset of the disorder usually after intensive care } \\
\text { unit admission }\end{array}$ & $\begin{array}{l}\text { Onset of the disorder usually before intensive } \\
\text { care unit admission }\end{array}$ \\
\hline & $\begin{array}{l}\text { Often characterized by fairly symmetric limb } \\
\text { muscle weakness sparing cranial nerves; }\end{array}$ & $\begin{array}{l}\text { Infections precede the onset of progressive } \\
\text { weakness and sensory disturbances }\end{array}$ \\
\hline & Sensory deficits less prominent & Frequent cranial nerve involvement \\
\hline Cerebrospinal fluid & Usually normal & Albumin-cytologic dissociation \\
\hline Electrophysiology & Axonal motor and sensory polyneuropathy & $\begin{array}{l}\text { Demyelinating polyneuropathy or unresponsive } \\
\text { nerves, abundant spontaneous activity } \\
\text { Axonal motor and sensory polyneuropathy }\end{array}$ \\
\hline Nerve ultrasound & $\begin{array}{l}\text { Elevated mean muscle echotexture and } \\
\text { fasciculations in more arm and leg muscle } \\
\text { groups with lower punctuations at the } \\
\text { ultrasound pattern scores (UPS) at the } \\
\text { examination of peripheral sensorimotor nerves } \\
\text { (A), roots and vagus (B), and sural nerve (C) }\end{array}$ & $\begin{array}{l}\text { Sonographic evidence of higher cross-sectional } \\
\text { area values (CSA) of the ulnar, radial, tibial nerve } \\
\text { and brachial plexus with higher punctuations at } \\
\text { the ultrasound pattern scores at the examination } \\
\text { of peripheral sensorimotor nerves (A), roots and } \\
\text { vagus (B), and sural nerve (C) }\end{array}$ \\
\hline $\begin{array}{l}\text { Magnetic resonance } \\
\text { imaging }\end{array}$ & No significant findings & Occasional enhancement of spinal nerve roots \\
\hline Biopsy & $\begin{array}{l}\text { Primarily axonal degeneration of distal } \\
\text { peripheral nerves without inflammation }\end{array}$ & $\begin{array}{l}\text { Primarily demyelinating process with } \\
\text { inflammation, or motor/sensory axonal } \\
\text { degeneration, or motor axonal degeneration only }\end{array}$ \\
\hline Treatment & No specific therapy, usually anti-septic treatment & Plasmapheresis, intravenous immune globulin \\
\hline Outcome & $\begin{array}{l}\text { Recovery may be spontaneous and of variable } \\
\text { timing; } 50 \% \text { of patients with full recovery }\end{array}$ & Usually $>75 \%$ complete recovery \\
\hline
\end{tabular}

Table III. Differentiation between critical illness polyneuropathy (CIP) and Guillain-Barré syndrome (GBS)

with no plausible cause other than critical illness. ICU-AW, with documented polyneuropathy, myopathy, or both, can be subclassified.

CIP refers to ICU-AW with electrophysiological evidence of an axonal polyneuropathy. CIM refers to ICU-acquired weakness with myopathy that is documented electrophysiologically or histologically. CINM refers to electrophysiological or histologic findings of both CIP and CIM [10,12]. Knowledge of clinical background in which the weakness evolves is an essential guide to differential diagnosis. CIP often follows sepsis [30], SIRS [28,29] and MODS [26]. CIM often occurs in the setting of treatment with intravenous corticosteroids [26] and non-depolarizing neuromuscular blocking agents [31,32], such as in patients with asthma, pneumonia, organ transplant, and renal failure [7,16,24,31,37]. The contribution of electrophysiological studies has been invaluable in identifying the different clinical forms $[4-6,8,11,24,42]$. However, there are some difficulties to define electromyography and nerve conduction studies as accurate $[4-6,8,11,24]$. They are difficult to perform in many critically ill patients. The patients must be awake and able to collaborate; patients in the ICU are often not able to contract their muscles voluntarily. Tissue edema can confound nerve conduction studies. Further investigation with biochemical studies and muscle biopsy are often necessary to arrive at a definitive diagnosis. Elevation of creatine kinase (CK) levels is associated with muscle necrosis but is not of diagnostic use on its own due to low sensitivity. Muscle biopsy in ICU paralysis syndromes may be helpful in arriving at an accurate diagnosis or to classify the type of CIM. Nerve biopsy is only rarely indicated. Clinical, electrophysiological, and histological features of ICU-AW are summarized in Table III. 


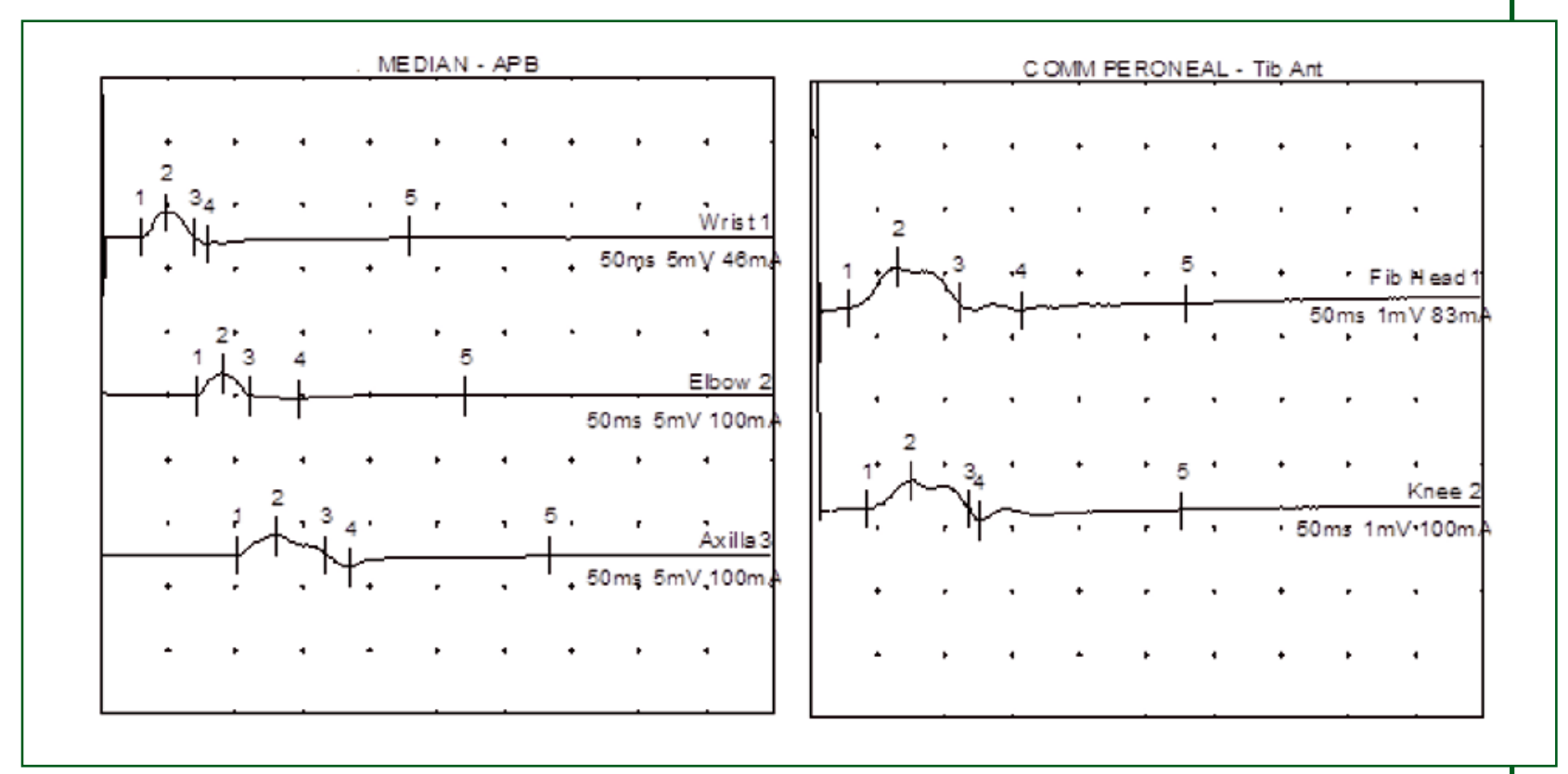

Figure 1. Typical nerve conduction studies in presence of CIP registered on median and common peroneal nerve and derived from abductor brevis pollicis (ABP) and anterior tibialis (Tib Ant), respectively. In CIP, CMAP amplitude is reduced (corresponding to loss of axons), with normal conduction velocity in surviving axons

\section{Electromyography and nerve conduction studies}

Electromyography is an essential method of making a final or differential diagnosis. A reduction in the amplitude of compound muscle action potentials (CMAP) or sensory nerve action potentials (SNAP), or both, with preserved conduction velocity and normal distal motor latencies, in addition to normal responses to repetitive nerve stimulation, may be seen within 2-5 days after the onset of symptoms. The reduction in amplitude often precedes clinical presentation and accompanying fibrillation potentials and positive sharp waves that may occur in the second or third week (Figure 1) [43]. The duration of CMAPs is an important indicator of CIM, and it accompanies the fall in amplitude [43]. CMAP duration can be 2-3 times longer compared to healthy controls and is most pronounced in lower limb nerves (Figure 2).

Electrophysiological screening is showing CMAP duration reductions below two standard deviations of the normal value accurately iden-

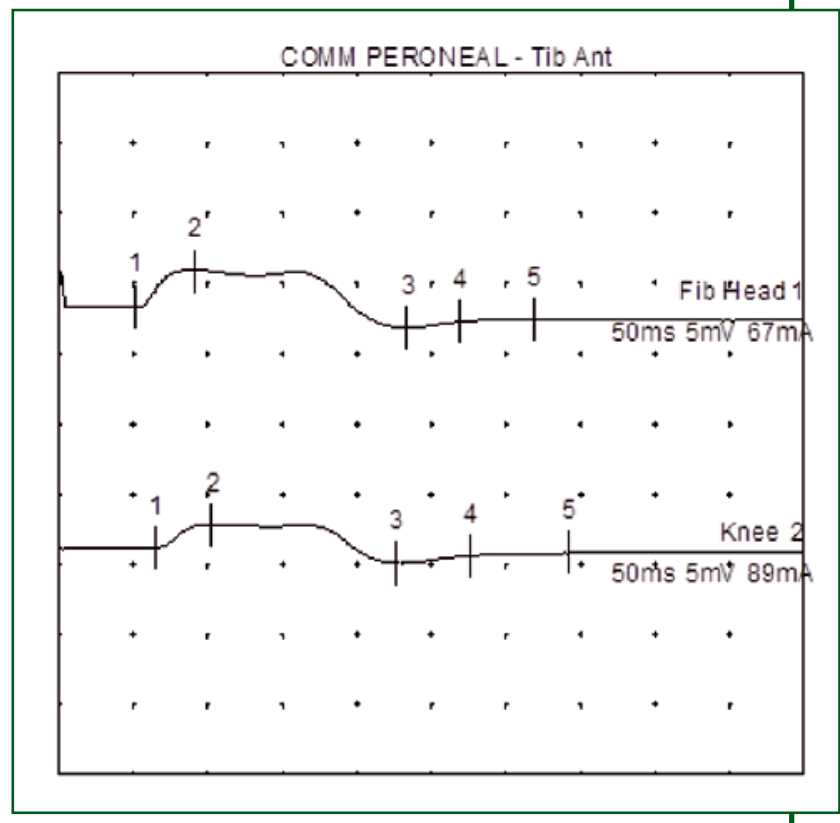

Figure 2. Typical nerve conduction study in presence of CIM registered on common peroneal nerve and derived from anterior tibialis (Tib Ant). In CIM, CMAP amplitude is reduced, together with an increase of CMAP duration with normal conduction velocity. Sarcolemmal inexcitability causes low amplitude CMAPs) that may have prolonged durations 
tifies patients with CIP or CIM, increased duration of CMAP will permit to identify patients with CIM $[44,45]$. Patients admitted for sepsis or SIRS showing electromyographic signs of characteristic CMAP potentials in early stages, and an abnormal baseline nerve conduction study are more likely to develop acquired neuromuscular dysfunction with increased hospital mortality [44].

Baum et al. [45] identified four different clusters of electrophysiological impairment in patients with sepsis/SIRS, which enabled further differentiation of the severity of neuromuscular disturbances in sepsis-associated organ failure:

- Cluster 1: normal values for CMAP, SNAP, and nerve conduction velocity in all nerves, which accounted for $10 \%$ of total patients;

- Cluster 2: pathological values for CMAP in the lower extremities and other parameters normal, which accounted for $17 \%$ of patients;

- Cluster 3: moderate pathological values for CMAP, SNAP, and sensory nerve conduction velocity in upper and lower extremities and motor nerve conduction velocity in lower extremities, which accounted for $40 \%$ of patients;

- Cluster 4: severe disturbances of CMAP, SNAP, and nerve conduction velocity in upper and lower extremities, which accounted for $33 \%$ of patients.

Varying degrees of fibrillation potentials and positive sharp waves can be recorded in both CIP and CIM. Abnormal SNAPs are characteristic for CIP, although local edema may interfere with optimal sensory nerve stimulation and recording. CIM is characterized by significant slowing of the muscle fiber conduction velocity or even muscle fiber conduction block during the acute phase, which correlates with a prolonged CMAP duration and altered muscle fiber excitability [43]. The earliest electrophysiological sign of CIP is a reduction of CMAP amplitudes, with a minor change in latency. These changes are typical of axonal damage but are also associated with severe myopathy, including CIM. Fibrillation potentials and positive sharp waves may not appear in the muscle until 3 weeks after onset. Motor unit potentials (MUP), if they can be voluntarily activated by the patient, will often appear polyphasic and normal or somewhat low in amplitude, suggesting an associated primary involvement of muscle. These electrophysiologic changes, however, are not specific and are also produced by a primary myopathy. Despite electrodiagnostic technical difficulty in critically ill patients, it is important to demonstrate a reduction of SNAP amplitudes before a firm electrophysiologic diagnosis of polyneuropathy can be made; this finding is not present in many instances. There is some evidence that some patients with CIM demonstrate increased CMAP duration [46], but this finding needed further validation. In support of that, in vitro single muscle fiber excitability studies have demonstrated a reduction in muscle fiber conduction velocity that is inversely proportional to the degree of muscle weakness in CIM [47]. The CMAP amplitude prolongation was also proportional to the degree of weakness and phase of illness.

A simplified screening method of ICU-AW is based on the daily measurement of peroneal CMAP amplitude [48]. In a prospective multicenter study of 92 intensive care unit patients, a reduced CMAP amplitude on peroneal nerve by more than 2 standard deviations predicts neuromuscular complications of critical illness within a $67 \%$ specificity [48]. All affected patients developed the electrophysiological change within 13 days of intensive care unit admission with a median time of 6 days. This change in CMAP amplitude was abrupt over 1 day in most cases but took place over several days in others.

Repetitive nerve stimulation studies to demonstrate a defect in neuromuscular transmission should also be performed in suspicious cases. This defect does not occur in sepsis but will be present if neuromuscular blocking agents have been used. Their effects may persist beyond several hours for a number of days if the patient is in renal failure or liver failure [45]. Phrenic nerve conduction studies and, in some cases, needle electromyography of chest wall muscles and the diaphragm are safe and can establish respiratory muscle involvement in patients who are difficult to wean from the ventilator [50]. Electrophysiological features of CIM include reduction of CMAP amplitudes (less than 80\%) and 
perhaps in some cases increased duration in 2 or more nerves with normal or near normal sensory nerve action potential amplitudes (more than $80 \%$ ). There should be an absence of decrement on repetitive nerve stimulation. Myopathic changes should be seen on needle examination, with or without fibrillation potentials [51].

Tzanis et al. [52] have proposed that maximum inspiratory pressure may serve as a surrogate indicator for the assessment of CIP and CIM. The authors measured maximum inspiratory pressure using the unidirectional valve method, independent of the patient's ability to cooperate. A significant correlation was found between maximum inspiratory pressure and the MRC scale score $(r=0.68, P<0.001)$ [52]. The findings indicated that maximum inspiratory pressure, estimated using the unidirectional valve method, may be useful for early detection of intensive care unit-acquired weakness [52]. Electrophysiological findings should always be correlated with clinical findings. In difficult cases, muscle biopsy may be required for a definite diagnosis.

\section{Direct muscle stimulation (DMS)}

To overcome the challenges of patient cooperation and completely avoid muscle biopsy, the method of DMS has been evaluated. First proposed by Rich et al. in 1996 [53], DMS was intended to differentiate between CIM and CIP. Both conditions demonstrate reduced nerve-evoked CMAP amplitude. Yet denervated muscle (as in CIP) should retain electrical excitability and after DMS, CMAP amplitude should be normal. CIM patients should exhibit loss of electrical excitability and both nerve- and after DMS, CMAPs should be diminished. The ratio of nerve stimulated CMAP to muscle stimulated CMAP amplitude should be more than 0.5 in CIM (and in normal controls) and less than 0.5 in CIP. Trojaborg and colleagues [35] applied those techniques in addition to the motor unit number estimates and quantitative electromyography to classify 22 consecutive patients with critical illness related weakness as having primarily neurogenic or myopathic features. These authors found that electrophysiological abnormalities supported a myopathy in all cases.

\section{Muscle and nerve ultrasounds}

Muscle and nerve ultrasounds appear as a new tool that can help to establish and early diagnosis of this entity [54,55]. In CIM, a controlled and observational study in patients with sepsis showed muscular fasciculations more frequently and in greater numbers of regions affected principally in proximal and distal arms and legs, additionally, 75\% of them had alterations in normal echotexture of examined muscles [55]. In the same manner, the use of ultrasound pattern sum score (UPSS) and its sub-scores can help in identify CIP [54]. These methods until now are under investigation and cannot replace electroneuromyography and nerve conduction studies or muscular biopsy although showing high sensitivity, specificity, and predictive positive values.

\section{Muscle biopsy}

Muscle biopsy is still considered the gold standard for confirming muscle involvement in the disease process despite its invasiveness. Critical illness myopathy is pathologically classified into five subtypes: (1) thick filament myopathy; (2) acute myopathy with scattered necrosis; (3) acute myopathy with diffuse necrosis; (4) disuse cachectic myopathy; and (5) rhabdomyolysis (Figure 3) [8,38].

Although unusual, myopathy can progress to frank rhabdomyolysis. CIP presents as morphological signs of axonal degeneration in both type 1 and type 2 fibers, resulting in extensive denervation atrophy of muscles. During recovery, muscle biopsy may show grouped atrophy of muscle fibers. Furthermore, angular atrophy of isolated scattered muscle fibers has been observed as part of an acute denervation process $[8,38]$. However, clinical characteristics and examination results should be carefully evaluated for the correct diagnosis of CIP and CIM $[8,38]$. 


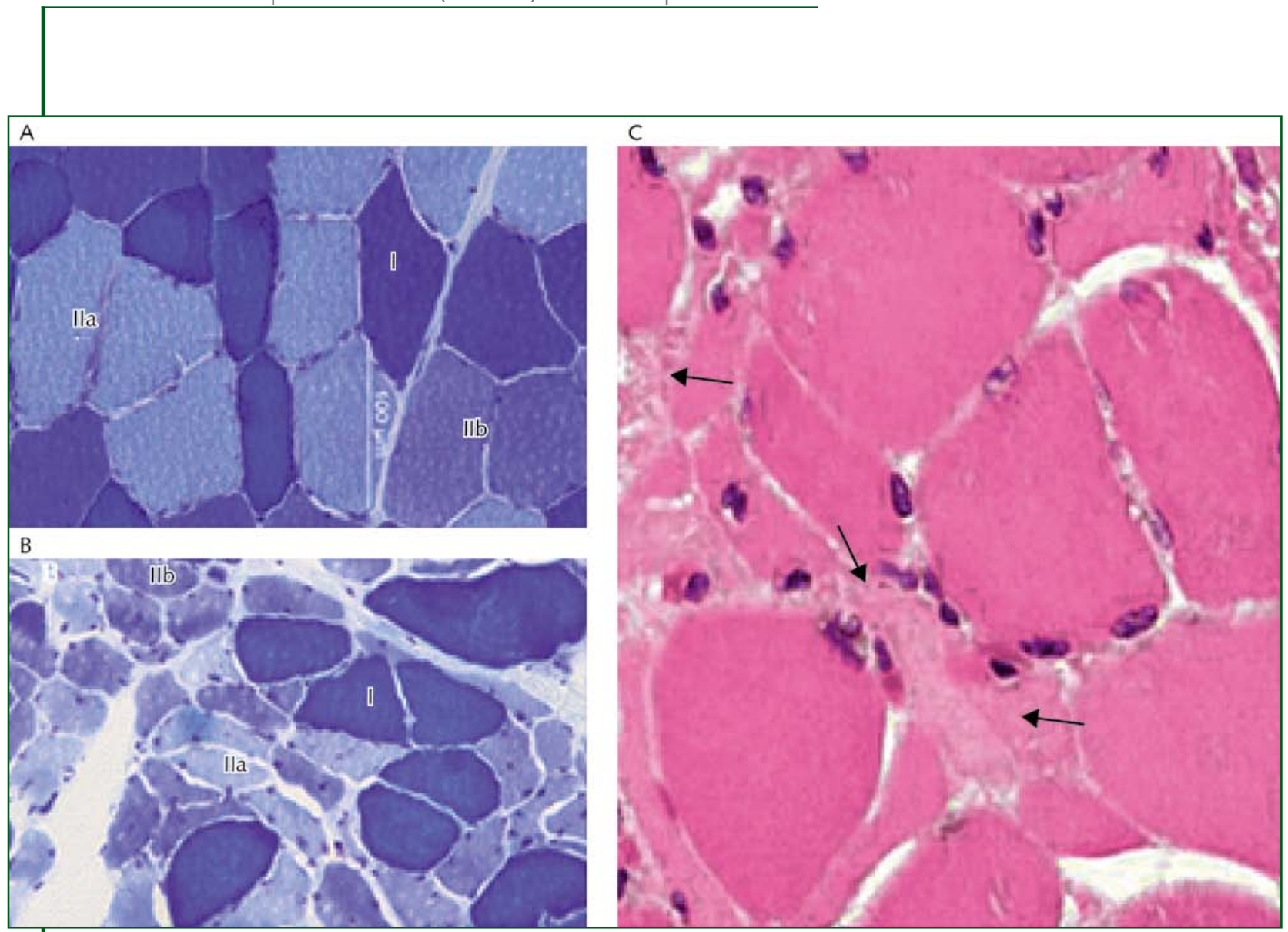

Figure 3. Muscle biopsy (vastus lateralis muscle) from a normal subject (A). ATPase/Toludine blue staining differentiates type I, Ila and IIb muscle fibres as indicated. (B) CIM. A predominant type II (fast twitch) muscle fibre atrophy. (C) Hematoxylin-eosin staining in CIM. Atrophic fibers stained poorly, and in some fibers, a feathery degeneration of the cytoplasmic content was seen (arrows)

\section{ICU-AW clinical subtypes}

\section{Critical illness polyneuropathy (CIP)}

CIP is a diffuse and symmetric sensorimotor axonal neuropathy [30]. In CIP we can observe a distal loss of sensitivity to pain, vibration, and temperature, and often the patients have difficult to breath spontaneously or to be weaned from mechanical ventilation due to phrenic nerve and diaphragm involvement [25,50]. The mechanism of axonal degeneration may be multifactorial, including: impaired oxygen and nutrient delivery from microcirculatory dysfunction in peripheral nerves, due to sepsis and/or hyperglycemia, and increased endoneuronal edema, due to cytokine-induced changes in microvascular permeability; and neuronal bioenergetics failure from mitochondrial dysfunction, due to increased uptake of glucose and subsequent reactive oxygen species generation $[4,8,38]$. Furthermore, cytokines may exert direct toxic effects on peripheral nerves, and there may be a humoral neurotoxic factor involved in the pathogenesis of CIP $[4,8,38]$. The morphologic features of CIP have been demonstrated through the biopsy of peripheral nerve and muscle [5]. There is a primary axonal degeneration of peripheral nerve motor and sensory fibers, but no evidence of inflammation, as may be seen in GBS. Muscle shows scattered atrophic fibers in acute denervation and grouped atrophy in chronic denervation. Immunohistochemistry of muscle biopsy specimens demonstrates upregulation of HLA-DR, the proinflammatory cytokine tumor necrosis factor-R75, and the anti-inflammatory cytokine IL-10 when 
compared to controls [56]. The only CNS manifestation is central chromatolysis of anterior horn cells and loss of dorsal root ganglion cells, secondary to the peripheral nerve axonal damage. No changes appear distinctive of CIP. A definite diagnosis of CIP requires that the following criteria be met: (1) The critically ill patient develops limb weakness or difficulty in weaning, after non-neuromuscular causes such as heart and lung diseases have been excluded; (2) electromyography shows axonal motor and sensory polyneuropathy; (3) absent decremental response to repetitive nerve stimulation [57].

\section{Critical illness myopathy (CIM)}

CIM occurs more frequently than CIP, and it is associated with a higher rate of recovery [58]. CIM represents a spectrum of ICU-acquired muscle pathology involving metabolic, inflammatory, and bioenergetics muscle derangements. CIM patients characteristically have early loss of muscle tissue (cachexy myopathy), but with conservation or slightly reduced deep tendon reflexes. In CIM, levels of CK are often high, and others blood exams can show evidence of SIRS, sepsis, and multiorgan compromise [7,24,38,59]. Frequently high levels of CK are observed [7,24,38,60]. Decreased oxygen and nutrient delivery to muscles, upregulation of protein catabolism by pro-inflammatory cytokines, decreased expression of myofibrillar repair genes, and an imbalance in anabolic and catabolic hormones contribute to CIM. The reported light-microscopic findings in specimens from CIM patients include muscle fiber atrophy (preferentially type II fibers), occasional fiber necrosis, regeneration, and decreased or absent reactivity in myofibrillar adenosine triphosphatase staining, corresponding to a selective loss of myosin filaments. This selective loss of myosin is practically pathognomonic for CIM [51,61]. To minimize the morbidity of an open muscle biopsy, some have proposed quantification of myosin/actin ratio by gel electrophoresis in core needle specimens (conchotome muscle biopsy technique) to diagnose CIM [62]. A definite diagnosis of CIM requires that the following criteria be met: (1) The critically ill patient develops limb weakness or difficulty weaning, after non-neuromuscular causes such as heart and lung diseases have been excluded; (2) compound muscle action potential amplitudes are less than $80 \%$ of the normal lower limit in two or more nerves without conduction block; (3) sensory nerve action potential amplitudes are greater than $80 \%$ of the normal lower limit; (4) needle electromyography shows short duration, low-amplitude motor unit potentials with early or normal full recruitment, with or without fibrillation potentials, in conscious and collaborative patients, or increased compound muscle action potential duration or reduced muscle membrane excitability by direct muscle stimulation in non-collaborative patients; (5) absent decremental response to repetitive nerve stimulation; (6) muscle histopathology shows primary myopathy [57].

\section{Critical illness polyneuromyopathy (CINM)}

CIP and CIM often coexist, commonly referred to collectively as CINM. Muscle that is functionally denervated (from CIP) and directly injured (from CIM) may have increased susceptibility to additional insults and injury (e.g., corticosteroid-induced myopathy). Furthermore, weakness from CINM may be enhanced by immobility [25]. When sought, myopathy is often present in conjunction with the established evidence for neuropathy $[8,25]$. For example, Latronico et al. demonstrated that 19 of 24 patients with CIP had evidence of myopathy when muscle biopsy was performed [25].

\section{Prolonged neuromuscular blockade (PNB)}

The condition may coexist with CIP or CIM and has been reported to progress to CIM on sequential studies. They are patients treated with high doses of nondepolarizing neuromuscular blocking agents such as vecuronium and pancuronium may have persistent weakness and fail weaning from the ventilator, even after the blocking drugs have been discontinued [43,49]. Examination shows generalized weakness, normal or reduced reflexes, and normal sensation. Bilateral ptosis and facial and jaw muscle 


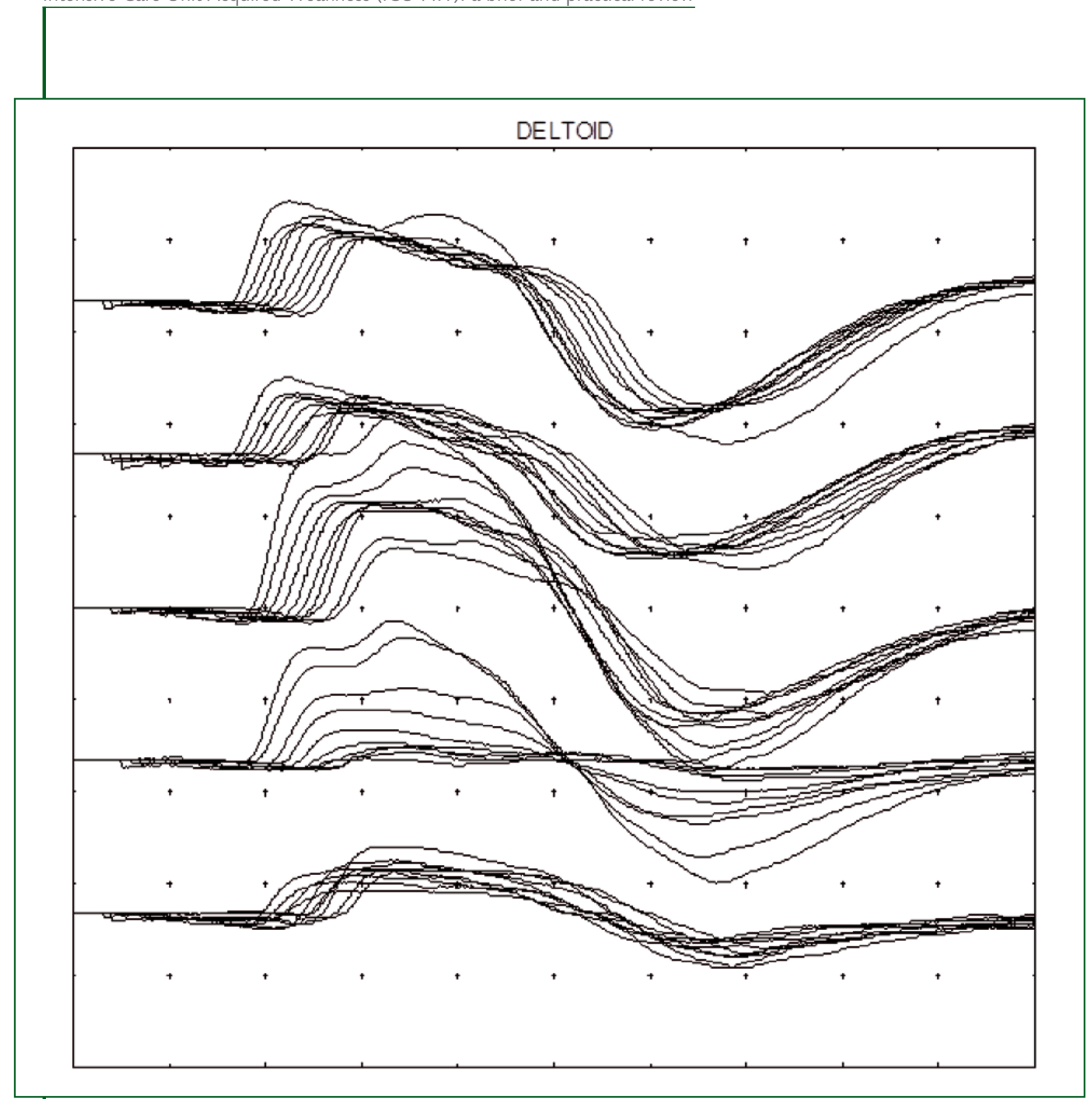

Figure 4. Repetitive nerve stimulation at a low stimulation rate $(3-5 \mathrm{~Hz})$ in a patient with prolonged neuromuscular junction blockade. Decrement response suggests neuromuscular transmission defect

weakness may be present [43]. Electrophysiologic features are reduced CMAP amplitude and decrementing the response on $2-3 \mathrm{~Hz}$ repetitive nerve stimulation (Figure 4). Patients with uncomplicated prolonged neuromuscular blockade recover completely, usually in 1-2 weeks.

\section{Proposed diagnostic algorithm}

To optimize the likelihood of patient interaction for neuromuscular assessments, we advocate the implementation of sedation protocols. Daily interruption of sedative infusions confers the opportunity for serial neuromuscular examination and reduces the duration of mechanical ventilation [63]. Careful implementation of the structured MRC examination should be employed and documented serially as 


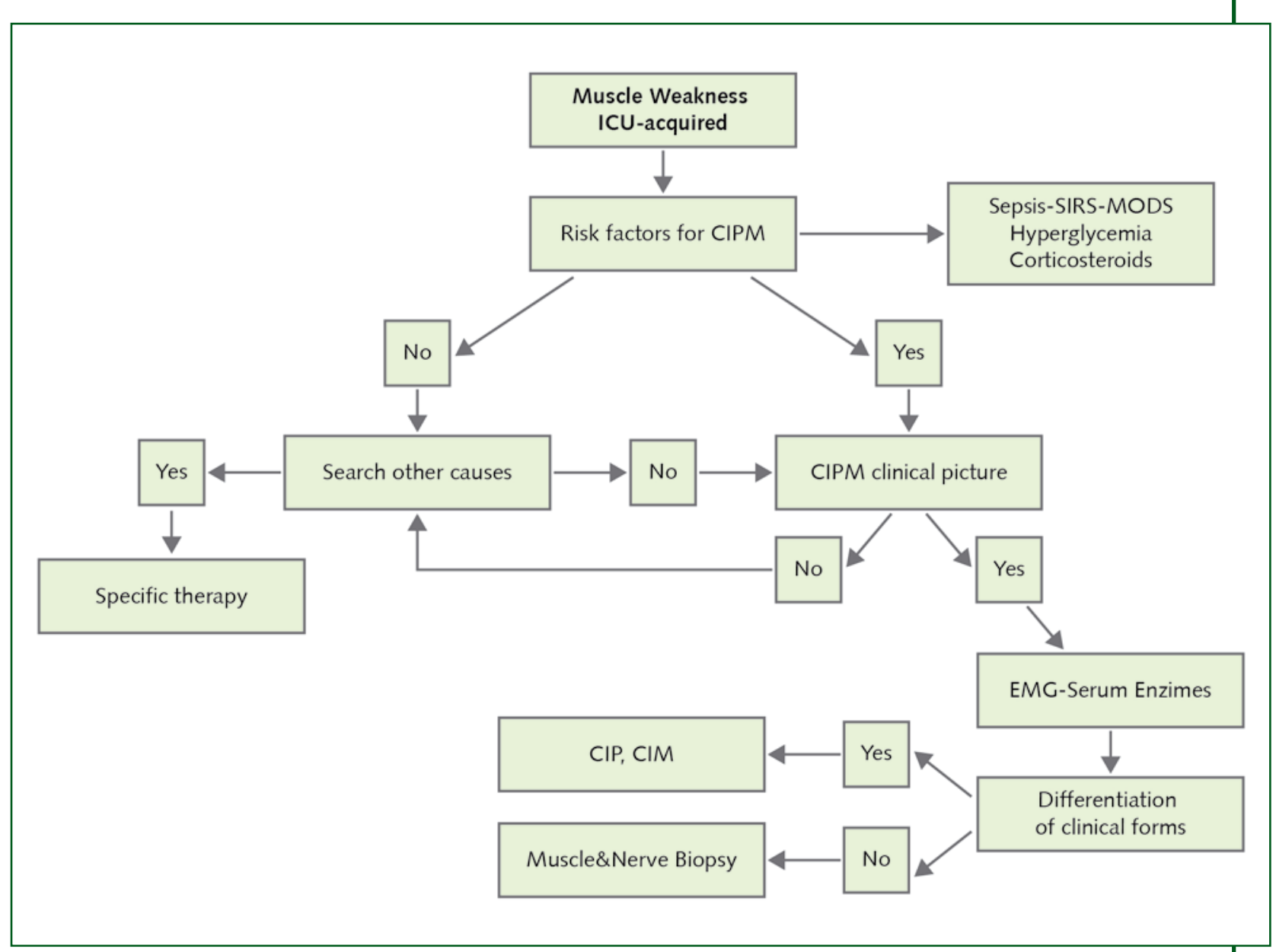

Figure 5. Practical algorithm for diagnosis of critical illness polyneuromyopathy

a matter of routine. Patients exhibiting fixed or focal motor defects or persistent altered sensorium despite adequate sedation washout should undergo more advanced diagnostics (i.e., CNS imaging, electrophysiologic studies, and/or muscle biopsy) (Figure 5).

The decision to perform electrophysiologic testing and/or muscle biopsy in routine care has created an ongoing debate in the medical literature about its utility. Advocates for routine clinical examination who reserve neurophysiological testing and biopsy for unusual or severe instances of weakness cite the limitations, costs, and risks of this testing is an useful and efficient strategy. Establishing a highly specific or physiologically based diagnosis does not translate to a specific pharmacologic therapy. Furthermore, therapies currently employed to limit ICU-AW should be applied to virtually all critically ill patients receiving mechanical ventilation.

\section{Pathophysiological mechanisms}

During the evolution of critical illness differents mechanisms of injury trigger and feedback to develop an adverse microenvironment for muscles and nerves. The muscular and nervous affectation does not escape the systemic involvement of different organs as a result of massive release of cytokines and other mediators that activate different cascade of mediators which produce electrical, metabolic, microvascular and bioenergetic disturbances (Figure 6) $[8,28]$. 


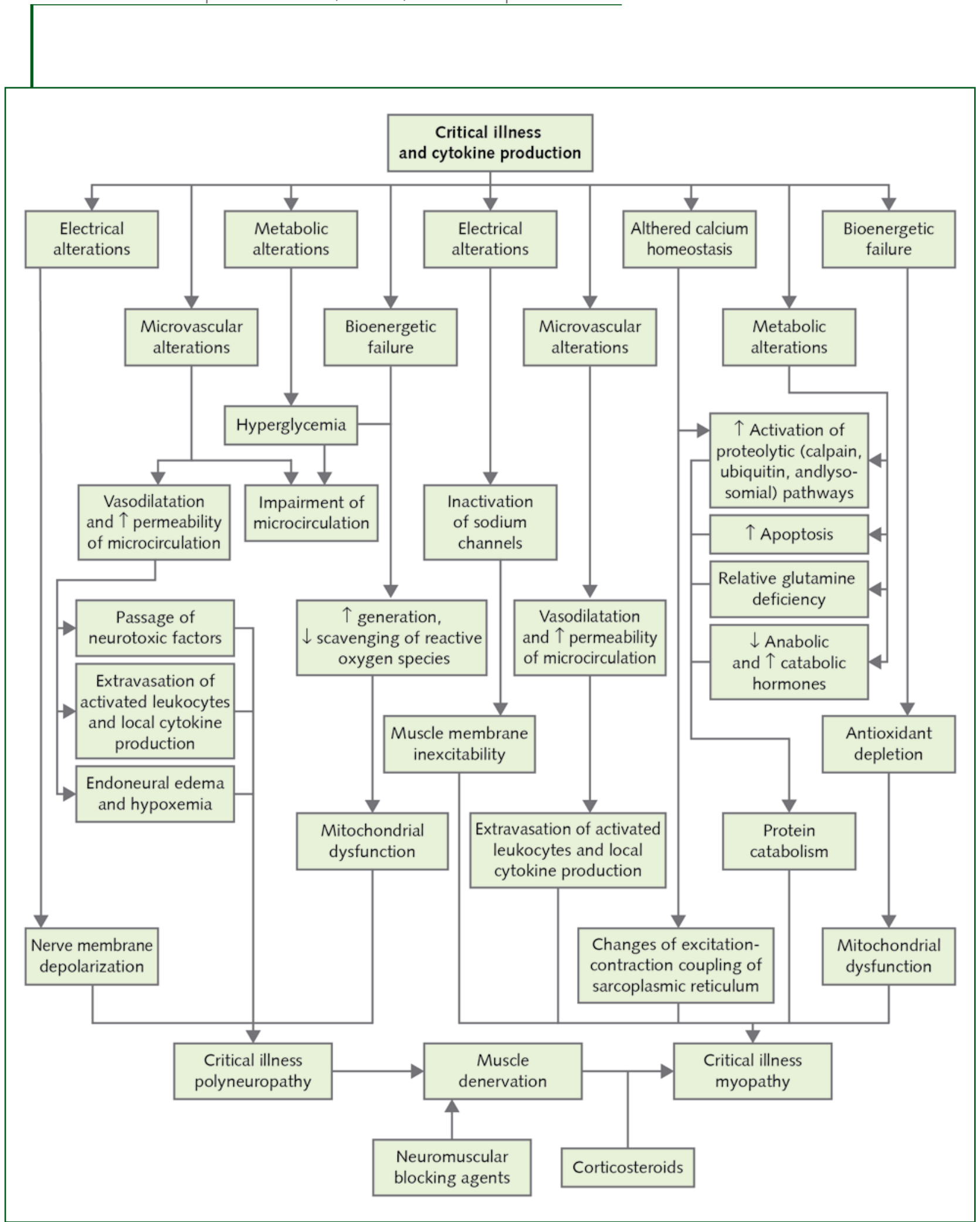

Figure 6. Pathophysiological mechanisms of ICU-AW

\section{Inactivation of sodium ion channels}

Rich and Pinter suggest that inactivation of sodium channels may contribute to critical illness related neuropathy, myopathy, or both [64]. During electrophysiological studies, severely affected muscle has been found to be electrically inexcitable to direct muscle stimulation [53]. In studies with animal 
models, this inexcitability has been proposed to be caused by changes (hyperpolarizing shift) in fast sodium channels leading to inexcitability of muscle fibers. In patients with septic shock, there are decreased QRS amplitudes and increased QRS duration; while, in patients who recovered from septic shock, the electrocardiographic findings return to normal [65]. These observations are consistent with the notion of an acquired channelopathy because of the strong association between severe sepsis and ICU-AW. This may result from post-translation modification of sodium channels by glycosylation or phosphorylation or from increased expression of the embryonic sodium channel isoform that causes a shift toward more negative potentials [64]. The inactivation of sodium channels provoke decrease or absence of nervous excitability, whereas in the muscles produce inactivity and decline of muscular strength. Biopsy specimens have demonstrated normal appearance of muscles and nerves or the presence of limited necrosis, suggesting that alterations in ICU-AW are primarily functional $[8,24]$.

\section{Metabolic changes}

Hyperglycemia, hyperosmolality, and hypoalbuminemia enhance muscular and nerve microvascular permeability, developing edema, reduce antioxidant capacity and affect the microcirculation due to thrombosis, edema and vasoconstriction [6]. Disturbances of the microcirculation to nerve and muscle may also explain the effects of neuromuscular blocking agents, corticosteroids, and antibiotics, particularly aminoglycosides with their known neural toxicity. However, there has been no statistical proof that antibiotics cause peripheral nerve dysfunction in sepsis [66]. Through increased capillary permeability induced by sepsis, neuromuscular blocking agents could have a direct toxic effect on peripheral nerve axons. These neuromuscular blocking agents may also cause functional denervation through their prolonged neuromuscular blocking action. A combination of functional denervation due to neuromuscular blocking agents and the subsequent direct effects of steroids together with protracted immobility and a high-stress catabolic state in muscle might be a possible mechanism. CIP and the additional effects of neuromuscular blocking agents could denervate muscle, and steroids could then induce the typical myopathic changes. Both the rapidly evolving myopathy reported by al-Lozi and colleagues, which is characterized by destruction of thick filaments throughout the muscle fibers [67], and the acute necrotizing myopathy of intensive care may simply represent further stages of this process [68].

\section{Microvascular changes}

The pathophysiological mechanisms of ICU-AW are multifactorial and commonly invoked pathways include ischemia or injury via mediators of inflammation [61]. How systemic inflammation would produce nerve and muscle injury is unclear. In animal studies, inflammation of muscle tissue was found, represented by cellular infiltration and increased local levels of various inflammatory mediators. In human studies, high levels of various inflammatory mediators were found in muscle and nerve tissue of ICU-AW patients [61]. The expression of adhesion molecules on vascular endothelium suggests the possible contribution of increased vascular permeability. Expression of E-selectin, induced by sepsis is significantly elevated in the endoneurial and epineural vessels of patients with suspected CIP, supporting the idea that microvascular changes may contribute to the axonopathy of CIP [69]. A dysfunctional microcirculation leads to neuronal injury and axonal degeneration.This is believed to play a role in perpetuating local inflammation in peripheral nerves which suggests the endothelial-cell activation as described in models of sepsis, with microvascular leak and alterations in the microvascular environment. Moreover, cytokines that are secreted in sepsis have histamine-like properties that may also increase microvascular permeability [5]. Increased capillary permeability induces local tissue edema and activation of nitric oxide, causes arteriolar dilation, which may further slow capillary flow. Blood vessels supplying the peripheral nerves lack autoregulation, rendering these vessels susceptible to such 
disturbances. Tissue injury leads to the influx of inflammatory cells and the release of inflammatory cytokines. While these local phenomena may be important, measurement of more global markers of inflammation, such as interleukin- 6 and tumor necrosis factor, has not shown them to be elevated in the serum of patients with CIP as compared to nonweak, critically ill control subjects [56]. Thus, essential nutrients fail to reach the organ parenchyma.

\section{Bioenergetic disturbances}

Severe energy deficits will result, inducing a primary axonal degeneration, most likely distally if highly energy-dependent systems involving axonal transport of structural proteins are involved. Bioenergetic failure is principally due to mitochondrial dysfunction with impaired capacity to generate ATP. Greater mitochondrial dysfunction has been observed in the skeletal muscle of patients who died from critical illness than in that of survivors of critical illness [44]. Hyperglycemia may also exacerbate this problem, perhaps by inducing neural mitochondrial dysfunction [61]. Failure of GLUT4 translocation from the perinuclear spaces to the sarcolemmal membrane was demonstrated to be a central mechanism of impaired glucose supply to muscle cells in CIM patients. There is a significant insulin resistance in critically ill patients as compared to healthy control subjects; insulin resistance is most severe in CIM patients. Electrical muscle stimulation corrected muscle-specific adenosine monophosphate-activated protein kinase failure, restored GLUT4 translocation in the sarcolemmal membrane, and prevented type-2 fiber atrophy in CIM patients [70].

\section{Cellular apoptosis}

Changes in calcium $\left(\mathrm{Ca}^{++}\right)$homeostasis increases apoptosis and activation of proteolytic pathways. Different proteins degradative and apoptotic systems are found in muscle that have been implicated in CIM. Fiber atrophy is associated with myosin filament depolymerization that may be caused by increased expression of lysosomal enzymes and ubiquitin [71]. Patients who developed severe weakness after receiving high-dose steroids showed increased ubiquitin expression [72]. This suggests that the ubiquitin-ATP-dependent proteolytic system may be initiated by corticosteroid use. Serum amyloid A1 transiently accumulates within the first few days in muscle of critical illness myopathy patients and is in vitro induced by interleukin 6 and tumor necrosis factor-alpha [72]. Upregulation of part of the apoptotic system, specifically TGF-beta/MAPK, has been found to be uniquely involved in CIM [74]. There is also evidence linking proteolytic and apoptotic systems as mechanisms of muscle fiber atrophy, necrosis, and cell death. Caspase-3-mediated apoptosis has been shown to cause extensive cell death in multiple organ systems during sepsis [75]. Furthermore, hormonal changes include relative deficiency of glutamine, decrease of anabolic hormones and increase of catabolic hormones [76].

\section{Protein degradation}

Other mechanisms that contribute to muscle wasting during critical illness are derived from protein degradation exacerbated by profound hypercatabolism and prolonged immobility, particularly those with sepsis [30]. Muscle atrophy begins just after few hours of bed rest associated with deep sedation, a situation that applies to all muscle groups of the body, including the diaphragm. In the diaphragm, mechanical ventilation is associated with increased activity of the ubiquitin proteasome system, decreased levels of myosin heavy chain, and increased atrophic protein kinase B-forkhead box subgroup O (AKT-FOXO) signaling [29]. Muscle inactivity is a potent stimulus for protease activation leading to muscle protein breakdown and activation of the ubiquitin pathway of proteolysis. Immobility of the extremities, which is common in patients in the ICU, is related to the underlying illness in conjunction with prescribed bed rest and sedative-related immobility. Together with ubiquitin-proteasome system multiple proteolytic systems are also involved in muscle fiber atrophy, cathepsin B, lysosomal enzymes, and heat shock protein 72 [71]. 


\section{Differential diagnoses}

Differential diagnoses of ICU-AW commonly include GBS, metabolic neuropathies, toxic neuropathies, and neuropathies due to nutritional deficiencies. GBS, usually presents as symmetric, progressive, and ascending paralysis, sensory abnormalities, and areflexia, and $30 \%$ of patients require mechanical ventilation [77]. The nerve conduction velocity test shows decreased velocity in typical GBS, whereas normal conduction velocity and decreased action potential, both features of axonal neuropathy, can be seen in CIP and in axonal variants of GBS [77]. The major clinical difference between CIP and axonal variants of GBS is that GBS may follow an antecedent infective illness, surgery, or trauma for which the patient may have been initially admitted to the ICU [77]. Differentiation between BS and CIP is essential for the determination of therapeutic strategies, as intravenous immunoglobulin or plasma exchange is required in GBS [77], while supportive care is needed in critical illness polyneuropathy. Onset of clinical signs and electrophysiological changes in peripheral nerves and muscles during the development of CIP and myopathy can be rapid [18,28,38,78,79]. Albumin-cytologic dissociation in cerebrospinal fluid can help differentiate between the two diseases. The cerebrospinal fluid protein concentrations in patients with GBS are usually normal at the beginning of the disease, and increase in over $90 \%$ of patients by the end of the second week [77], whereas protein concentrations are usually unchanged in CIP and CIM. Furthermore, a nerve biopsy and detection of anti-ganglioside antibodies could be helpful in differentiating critical illness polyneuropathy from axonal GBS [77]. The criteria for differentiation are specified in Table IV.

Ionic abnormalities such as hypokalemia, hypophosphatemia, and hypermagnesemia, in addition to the use of several drugs including neuromuscular blocking agents, cancer chemotherapy, statins, and

\begin{tabular}{|llll|}
\hline \multicolumn{1}{|c}{ CIP } & \multicolumn{1}{c}{ CIM } & \multicolumn{1}{c|}{ CINM } \\
Physical & - Distal muscle weakness & - Proximal muscle weakness & - Proximal and distal muscle \\
examination & - Distal sensory deficit & - Normal sensory testing & weakness \\
& - Normal or depressed deep & - Normal or depressed deep & - Distal sensory deficit \\
& tendon reflexes & tendon reflexes & - Depressed deep tendon \\
& & & reflexes \\
Electrophysiology & - Decreased CMAP and & - Decreased CMAP and normal & - Decreased CMAP and SNAP \\
studies & decreased SNAP & SNAP & - Decreased MUAP \\
& - Normal MUAP & - Decreased MUAP & - EMG shows short duration, \\
& - Normal or near-normal & - EMG shows short duration, & low-amplitude activity \\
Histology & - Axonal degeneration of distal & - Thick filament (myosin) loss, & - Axonal degeneration and \\
& - motor and sensory nerves & type II fiber (fast twitch) & evidence of loss in myosin, \\
& & atrophy, necrosis & type II fiber atrophy, and \\
& & necrosis
\end{tabular}

Table IV. Pathophysiological features of Intensive Care Unit-Acquired Weakness (ICU-AW).

$\mathrm{CIM}=$ critical illness myopathy; $\mathrm{CINM}=$ critical illness neuromyopathy; $\mathrm{CIP}=$ critical illness polyneuropathy; $\mathrm{CMAP}=$ compound muscle action potential; $\mathrm{EMG}=$ electromyography; $\mathrm{MUAP}=$ muscle unit action potential; SNAP= sensory nerve action potential. 
antiretrovirals, should be differentiated because each can affect neuromuscular transmission and cause muscle weakness [80-82]. Propofol infusion syndrome, a syndrome involving severe metabolic acidosis, cardiac failure, rhabdomyolysis, renal failure, and hypertriglyceridemia after high-dose propofol ( $5 \mathrm{mg} / \mathrm{kg} / \mathrm{h}$ ) administration for long periods ( $>48$ hours), is also seen in intensive care units and should be taken into consideration [83]. Mild, chronic polyneuropathies such as diabetic polyneuropathy may affect predominantly the nerves of respiration. After admission to the critical care unit, sepsis may worsen a preexisting polyneuropathy. Occasionally, defects in neuromuscular transmission, myasthenia gravis, and Lambert-Eaton myasthenic syndrome present with primary respiratory failure. Diagnostic considerations in this group include anoxic myelopathy, affecting mainly anterior horn cells, which may result from cardiac arrest, atherosclerosis, surgery of the aorta or severe pulmonary disease [84].

CK levels vary in CIM but are usually normal or mildly elevated, except in acute necrotizing myopathy where CK levels are high. The signature pathological finding is a distinctive loss of thick myosin filaments. However, there can be various degrees of type 1 or type 2 muscle fiber atrophy as well as necrosis [71]. In an observational study of the first week of critical illness myopathy, Bierbrauer and colleagues described histological evidence in the vastus lateralis muscle of selective type 2 fiber atrophy coupled with depletion of myosin heavy chain IIa isoform messenger RNA in patients with inexcitable peroneal muscle membrane as defined by distal CMAP amplitudes below $3.0 \mathrm{mV}$ [60]. There has been debate regarding the need for a muscle biopsy in patients with possible CIM [51,59]. The controversy surrounds whether the biopsy results alter treatment decisions. Although Lacomis and colleagues have listed histopathological findings of myosin loss as one of their diagnostic criteria, they do not advocate muscle biopsy in cases without apparent diagnostic uncertainty. Muscle ultrasound data from healthy controls were compared to that derived from septic patients in the first 2 weeks; most septic cases have elevated mean muscle echotexture and fasciculations in more arm and leg muscle groups [54,55].

There have been conflicting reports about the effect of critical illness neuromuscular complications on the intensive care unit mortality rate. A systematic literature review found no increase in adjusted mortality of intensive care unit patients with neuromuscular complications but demonstrated prolongation of mechanical ventilation and intensive care unit and hospital stay [10]. However, in a prospective cohort of severe sepsis cases who underwent weekly neurologic examinations and nerve conduction studies within 72 hours of developing severe sepsis, an abnormal baseline nerve conduction study was predictive of increased hospital mortality (55\%), whereas none of the patients with normal baseline nerve conduction studies died [85]. Most of the affected patients had electrophysiological evidence of both critical illness myopathy and critical illness neuropathy.

\section{Treatment and management}

In the absence of specific therapy, the management involves the close collaboration of neurologists, neurophysiologists, and intensivists. The therapeutic strategies should be directed to the control of sepsis, SIRS and organ dysfunction and includes antibiotics to counteract infection, surgical drainage of an infected focus, and the use of inotropic drugs and fluid replacement to control hypotension. Several attempts at controlling early stage of the SIRS have shown variable results. These attempts include monoclonal and polyclonal antibodies directed against bacterial endotoxin, monoclonal antibodies to tumor necrosis factor-alpha, fusion protein constructs of soluble tumor necrosis factor receptors, IL-1 receptor antagonists [86], the platelet activating factor receptor antagonist, BN5202 [87], and the $\mathrm{N}$-acetylcysteine [88]. There also was no beneficial effect of reducing disease severity using high intravenous immunoglobulins [89], and IgM-enriched intravenous immunoglobulin [90]. Avoiding 
or minimizing some pharmacological agents, such as corticosteroids and neuromuscular blocking agents represent the best strategy way for early recovering of muscle and nerve $[3,4,8,25]$. Both agents should be avoided or utilized at minor therapeutic dose and for shorter periods of time $[3,4,8,25]$. However, although the mean daily dose of corticosteroids may predict physical outcome at 1 year [91], a recent Cochrane review concluded there is no effect of corticosteroids on CIP, except for fewer new shock episodes [92]. Shortening the time in deep sedation is another useful strategy for preventing ICU-AW. Physical function at 1 and 2 years is negatively impacted by longer duration of ICU stay [93]. This strategy involves minimizing the sedation with the goal of getting patients up and out of bed. The discontinuation of deep sedation is a critical first step in optimizing patient activity and awareness. Deep sedation is associated with undesirable effects that can be avoided. It increases the possibility of hemodynamic instability, the incidence of delirium and prolongs the duration of mechanical ventilation with the associated risk of pneumonia ans sytemic infection that implies [7,8,21,94]. Moreover, profound sedation prolongs the time of immobilization and prevents adequate and effective rehabilitation favoring muscle atrophy $[7,8,21,94]$. Finally, over-sedation has economic consequences due to extension of stay in ICU and in the hospital. It is advisable as far as possible to implement protocols of daily interruption of sedation, in order to withdrawal as quickly as possible [94]. De Jonghe et al. noted that use of a sedation algorithm designed to allow patients to be more alert was associated with a $50 \%$ reduction in pressure sores, presumably because of reductions in sedative-related immobilization [95]. Furthermore, the interruption of daily sedative use during mechanical ventilation increases the percentage of days during which patients are awake and able to follow commands [63]. The changes in ICU care to reduce sedative use improve in-hospital activity levels in a group of patients in the medical ICU [96].

Currently, therapeutic interventions to prevent or attenuate ICU-acquired weakness and functional impairment after critical illness are limited to proper nutrition, moderate glucose control, early mobilization and rehabilitation $[7,8,34,21]$. To date, the role of nutritional and supplemental therapies include protein and amino acid supplementation, antioxidant therapy, and hormonal therapy [78]. However, studies examining nutritional supplementation are difficult to extrapolate to the treatment of ICU-AW, in that they typically focus on enhancement of the immune system or other global outcomes and not the correction of myopathy or neuropathy. Intake of specific substrates, such as glutamine and glutathione, might have a beneficial effect on recovering neuromuscular impairments in the critically ill patient. However, there are still no data to justify its use if the only purpose is to recover neuromuscular function, while aggressive renutrition schedules should be avoided in order to prevent re-nutrition syndrome and further deterioration of muscle function [78].

Insulin antagonizes the different routes of damage generated during hyperglycemia, and also has neuroprotective effects, so it is the agent of choice for blood glucose control strategies. Insulin exerts anti-inflammatory effects, endothelial protection, improvement of dyslipidemia, and neuroprotective effects in animals and is also an anabolic hormone [97]. Although intensive glucose control was earlier thought to be helpful in reducing the incidence and severity of critical illness polyneuropathy [31], the NICE-SUGAR Study argues against tight glucose control given the higher mortality risk associated with increased moderate to severe hypoglycemia [98]. Intensive insulin therapy should be avoided due to the risk of hypoglycemia $[97,99,100]$. The American Diabetes Association currently recommends target blood glucose of 144 to $180 \mathrm{mg}$ per deciliter to reduce the risk of hypoglycemia in critically ill patients [101]. Therefore, according to a 2014 Cochrane update, intensive insulin therapy reduces ICU-AW (risk ratio 0.65), and it reduces the duration of mechanical ventilation, intensive care unit stay, and 180-day mortality. Because hypoglycemia is a risk, Cochrane reviewers recommend that consequences and prevention of hypoglycemia need further study [92].

The implementation of an early mobility and intensive rehabilitation program improves outcomes in ICU-AW patients $[3,4,8,25]$. When compared with a case series of patients with ICUAW who 
did not receive structured physical therapy, evidence suggested those who receive physical rehabilitation were more frequently discharged home rather than to a rehabilitative facility, although confidence intervals included no difference [57]. Passive mobilization prevents muscle atrophy, profound venous thrombosis and decubitus ulcers. Physical and occupational therapies increase the possibility to achieve good functional outcomes. Daily exercises especially targeted to the diaphragm and respiratory muscles help greatly in the process of weaning from mechanical ventilation. Other interventions show promise, but fewer data proving patient benefit exists. Furthermore, execution of a rehabilitation program requires a collaborative effort among members of the multi-disciplinary team to coordinate, care for, and provide safe mobilization of patients in intensive care units. Finally, electrical muscle stimulation (EMS) may be an alternative therapy for patients who cannot actively exercise or others disabling comorbidities and in patients unable to cooperate [102]. This technique may maintain muscle strength and joint range of motion, improve outcomes of ventilation, and reduce activity limitations [103].

\section{Prognosis}

ICU-AW is associated with increased mortality rate and rehabilitation problems [104]. Rehabilitation therapy is likely to be beneficial in speeding the recovery of these patients [105]. Prognosis for recovery from CIM is more favorable than that of CIP alone [17], unless muscle necrosis is severe, or CINM [106]. Children fair better than adults for a favorable recovery was thought to be as low as 50\% [107]. However, if the polyneuropathy is severe, recovery may take months. In especially severe cases, recovery may not occur [6]. Neurophysiological studies performed at intervals can aid in determining prognosis of recovery [108].

\section{Conclusions}

ICU-AW is a frequent complication of critical illness. Recovery is often slow and incomplete in such patients, particularly those who are elderly. There are three principal clinical forms; CIP CIM, and the mixed form CINM. They are characterized by generalized muscle weakness including respiratory compromise that makes difficult to wean from mechanical ventilation. Electrophysiological studies can help in differential diagnosis. Occasionally, muscle biopsy is necessary. Aggressive treatment of risk factors is essential. Early diagnosis is important to apply all prevention measures that are needed. A multidisciplinary approach is essential and, due to the lacking of specific therapy, proper management is based on minimizing or avoiding triggers, controlling sepsis and inflammatory states, minimizing the use of sedation, strict glycemic control and early and aggressive plan of mobilization and rehabilitation to reduce muscle reconditioning and dysfunction.

Question for further research

There is some evidence that some patients with CIM demonstrate increased CMAP duration, but this finding needed further validation. 


\section{The review in brief}

Clinical question Because the diagnosis and the management of ICU-AW can be sometimes difficult, this narrative review aims to help in organizing a practical approach to the diagnosis and management of ICU-AW patients.

Type of review Narrative

Conclusions Electrophysiological studies can help in differential diagnosis, occasionally, muscle biopsy is necessary. Aggressive treatment of risk factors is essential. Early diagnosis is important to apply all prevention measures that are needed. A multidisciplinary approach is essential, proper management is based on minimizing or avoiding triggers, controlling sepsis and inflammatory states, minimizing the use of sedation, strict glycemic control and early and aggressive plan of mobilization and rehabilitation to reduce muscle reconditioning and dysfunction.

Limitation Lack of specific therapy.

\section{Reference}

1. Osler SW. The principles and practice of medicine: designed for the use of practitioners and students of medicine. New York: D. Appleton and Company, 1910

2. Bolton CF, Laverty DA, Brown JD, et al. Critically ill polyneuropathy: electrophysiological studies and differentiation from Guillain-Barre syndrome. J Neurol Neurosurg Psychiatry 1986; 49: 563-73; http://dx.doi.org/10.1136/jnnp.49.5.563

3. Bolton CF, Gilbert JJ, Hahn AF, et al. Polyneuropathy in critically ill patients. J Neurol Neurosurg Psychiatry 1984; 47: 1223-31; http://dx.doi.org/10.1136/jnnp.47.11.1223

4. Hermans G, De Jonghe B, Bruyninckx F, et al. Clinical review: Critical illness polyneuropathy and myopathy. Crit Care 2008; 12: 238; http://dx.doi.org/10.1186/cc7100

5. Zochodne DW, Bolton CF, Wells GA, et al. Critical illness polyneuropathy. A complication of sepsis and multiple organ failure. Brain 1987; 110: 819-41; http://dx.doi.org/10.1093/brain/110.4.819

6. Witt NJ, Zochodne DW, Bolton CF, et al. Peripheral nerve function in sepsis and multiple organ failure. Chest 1991; 99: 176-84; http://dx.doi.org/10.1378/chest.99.1.176

7. Latronico N, Fenzi F, Recupero D, et al. Critical illness myopathy and neuropathy. Lancet 1996; 347: 1579-82; http://dx.doi.org/10.1016/S0140-6736(96)91074-0

8. Latronico N, Bolton CF. Critical illness polyneuropathy and myopathy: a major cause of muscle weakness and paralysis. Lancet Neurol 2011; 10: 931-41; http://dx.doi.org/10.1016/S14744422(11)70178-8

9. De Jonghe B, Cook D, Sharshar T, et al. Acquired neuromuscular disorders in critically ill patients: a systematic review. Groupe de Reflexion et d'Etude sur les Neuromyopathies En Reanimation. Intensive Care Med 1998; 24: 1242-50; http://dx.doi.org/10.1007/s001340050757

10. Stevens RD, Dowdy DW, Michaels RK, et al. Neuromuscular dysfunction acquired in critical illness: a systematic review. Intensive Care Med 2007; 33: 1876-91; http://dx.doi.org/10.1007/ s00134-007-0772-2

11. Latronico N, Guarneri B, Alongi S, et al. Acute neuromuscular respiratory failure after ICU discharge. Report of five patients. Intensive Care Med 1999; 25: 1302-6; http://dx.doi.org/10.1007/ s001340051062

12. Stevens RD, Marshall SA, Cornblath DR, et al. A framework for diagnosing and classifying intensive care unit-acquired weakness. Crit Care Med 2009; 37(10 Suppl): S299-308; http://dx.doi. org/10.1097/CCM.0b013e3181b6ef67 
13. Schafernak KT, Bigio EH. West Nile virus encephalomyelitis with polio-like paralysis \& nigral degeneration. Can J Neurol Sci 2006; 33: 407-10; http://dx.doi.org/10.1017/S0317167100005370

14. Godoy DA, Mello LJ, Masotti L, Di Napoli M. The myasthenic patient in crisis: an update of the management in Neurointensive Care Unit. Arq Neuropsiquiatr 2013; 71: 627-39; http://dx.doi. org/10.1590/0004-282X20130108

15. Campellone JV, Lacomis D, Giuliani MJ, Kramer DJ. Mononeuropathies associated with liver transplantation. Muscle Nerve 1998; 21: 896-901; http://dx.doi.org/10.1002/(SICI)10974598(199807)21:7<896::AID-MUS7>3.0.CO;2-1

16. Douglass JA, Tuxen DV, Horne M, et al. Myopathy in severe asthma. Am Rev Respir Dis 1992; 146: 517-9; http://dx.doi.org/10.1164/ajrccm/146.2.517

17. Guarneri B, Bertolini G, Latronico N. Long-term outcome in patients with critical illness myopathy or neuropathy: the Italian multicentre CRIMYNE study. J Neurol Neurosurg Psychiatry 2008; 79: 838-41; http://dx.doi.org/10.1136/jnnp.2007.142430

18. Bercker S, Weber-Carstens S, Deja M, et al. Critical illness polyneuropathy and myopathy in patients with acute respiratory distress syndrome. Crit Care Med 2005; 33: 711-5; http://dx.doi. org/10.1097/01.CCM.0000157969.46388.A2

19. Hough CL, Steinberg KP, Taylor Thompson B, et al. Intensive care unit-acquired neuromyopathy and corticosteroids in survivors of persistent ARDS. Intensive Care Med 2009; 35: 63-8; http:// dx.doi.org/10.1007/s00134-008-1304-4

20. de Letter MA, Schmitz PI, Visser LH, et al. Risk factors for the development of polyneuropathy and myopathy in critically ill patients. Crit Care Med 2001; 29: 2281-6; http://dx.doi. org/10.1097/00003246-200112000-00008

21. Tennila A, Salmi T, Pettila V, et al. Early signs of critical illness polyneuropathy in ICU patients with systemic inflammatory response syndrome or sepsis. Intensive Care Med 2000; 26: 1360-3; http://dx.doi.org/10.1007/s001340000586

22. Garnacho-Montero J, Amaya-Villar R, Garcia-Garmendia JL, et al. Effect of critical illness polyneuropathy on the withdrawal from mechanical ventilation and the length of stay in septic patients. Crit Care Med 2005; 33: 349-54; http://dx.doi.org/10.1097/01.CCM.0000153521.41848.7E

23. Herridge MS, Cheung AM, Tansey CM, et al. One-year outcomes in survivors of the acute respiratory distress syndrome. N Engl J Med 2003; 348: 683-93; http://dx.doi.org/10.1056/ NEJMoa022450

24. Latronico N, Peli E, Botteri M. Critical illness myopathy and neuropathy. Curr Opin Crit Care 2005; 11: 126-32; http://dx.doi.org/10.1097/01.ccx.0000155357.24360.89

25. Latronico N. Neuromuscular alterations in the critically ill patient: critical illness myopathy, critical illness neuropathy, or both? Intensive Care Med 2003; 29: 1411-3; http://dx.doi.org/10.1007/ s00134-003-1884-y

26. Waldhausen E, Mingers B, Lippers $\mathrm{P}$, et al. Critical illness polyneuropathy due to parenteral nutrition. Intensive Care Med 1997; 23: 922-3

27. Marino PL, Millili JJ. Possible role of dietary lipids in critical illness polyneuropathy. Intensive Care Med 1998; 24: 87; http://dx.doi.org/10.1007/PL00003757

28. Kress JP, Hall JB. ICU-acquired weakness and recovery from critical illness. N Engl J Med 2014; 371: 287-8; http://dx.doi.org/10.1056/NEJMc1406274

29. Griffiths RD. The 1995 John M. Kinney International Award for Nutrition and Metabolism. Effect of passive stretching on the wasting of muscle in the critically ill: background. Nutrition 1997; 13: 70-4

30. Hamburg NM, McMackin CJ, Huang AL, et al. Physical inactivity rapidly induces insulin resistance and microvascular dysfunction in healthy volunteers. Arterioscler Thromb Vasc Biol 2007; 27: 2650-6; http://dx.doi.org/10.1161/ATVBAHA.107.153288 
31. Winkelman C. Inactivity and inflammation in the critically ill patient. Crit Care Clin 2007; 23 : 21-34; http://dx.doi.org/10.1016/j.ccc.2006.11.002

32. Kleyweg RP, van der Meche FG, Schmitz PI. Interobserver agreement in the assessment of muscle strength and functional abilities in Guillain-Barre syndrome. Muscle Nerve 1991; 14: 1103-9; http://dx.doi.org/10.1002/mus.880141111

33. De Jonghe B, Sharshar T, Lefaucheur JP, et al. Paresis acquired in the intensive care unit: a prospective multicenter study. JAMA 2002; 288: 2859-67; http://dx.doi.org/10.1001/jama.288.22.2859

34. Garnacho-Montero J, Madrazo-Osuna J, Garcia-Garmendia JL, et al. Critical illness polyneuropathy: risk factors and clinical consequences. A cohort study in septic patients. Intensive Care Med 2001; 27: 1288-96; http://dx.doi.org/10.1007/s001340101009

35. Jaber S, Petrof BJ, Jung B, et al. Rapidly progressive diaphragmatic weakness and injury during mechanical ventilation in humans. Am J Respir Crit Care Med 2011; 183: 364-71; http://dx.doi. org/10.1164/rccm.201004-06700C

36. Levine S, Biswas C, Dierov J, et al. Increased proteolysis, myosin depletion, and atrophic AKT-FOXO signaling in human diaphragm disuse. Am J Respir Crit Care Med 2011; 183: 483-90; http://dx.doi.org/10.1164/rccm.200910-1487OC

37. MacFarlane IA, Rosenthal FD. Severe myopathy after status asthmaticus. Lancet 1977; 2: 615; http://dx.doi.org/10.1016/S0140-6736(77)91471-4

38. Leatherman JW, Fluegel WL, David WS, et al. Muscle weakness in mechanically ventilated patients with severe asthma. Am J Respir Crit Care Med 1996; 153: 1686-90; http://dx.doi.org/10.1164/ ajrccm.153.5.8630621

39. Hund E. Myopathy in critically ill patients. Crit Care Med 1999; 27: 2544-7; http://dx.doi. org/10.1097/00003246-199911000-00036

40. Koch S, Spuler S, Deja M, et al. Critical illness myopathy is frequent: accompanying neuropathy protracts ICU discharge. J Neurol Neurosurg Psychiatry 2011; 82: 287-93; http://dx.doi.org/10.1136/ jnnp.2009.192997

41. Lacomis D. Electrophysiology of neuromuscular disorders in critical illness. Muscle Nerve 2013; 47: 452-63; http://dx.doi.org/10.1002/mus.23615

42. Carre JE, Orban JC, Re L, et al. Survival in critical illness is associated with early activation of mitochondrial biogenesis. Am J Respir Crit Care Med 2010; 182: 745-51; http://dx.doi.org/10.1164/ rccm.201003-0326OC

43. Baum P, Bercker S, Villmann T, et al. Critical illness myopathy and neuropathy (CRIMYN). Electroneurographic classification. Nervenarzt 2011; 82: 468-74; http://dx.doi.org/10.1007/ s00115-010-3094-5

44. Goodman BP, Harper CM, Boon AJ. Prolonged compound muscle action potential duration in critical illness myopathy. Muscle Nerve 2009; 40: 1040-2; http://dx.doi.org/10.1002/mus.21445

45. Allen DC, Arunachalam R, Mills KR. Critical illness myopathy: further evidence from muscle-fiber excitability studies of an acquired channelopathy. Muscle Nerve 2008; 37: 14-22; http://dx.doi. org/10.1002/mus.20884

46. Latronico N, Bertolini G, Guarneri B, et al. Simplified electrophysiological evaluation of peripheral nerves in critically ill patients: the Italian multi-centre CRIMYNE study. Crit Care 2007; 11: R11; http://dx.doi.org/10.1186/cc5671

47. Segredo V, Caldwell JE, Matthay MA, et al. Persistent paralysis in critically ill patients after long-term administration of vecuronium. NEngl J Med 1992; 327: 524-8; http://dx.doi.org/10.1056/ NEJM199208203270804

48. Bolton CF. AAEM minimonograph \#40: clinical neurophysiology of the respiratory system. Muscle Nerve 1993; 16: 809-18; http://dx.doi.org/10.1002/mus.880160802 
49. Lacomis D, Zochodne DW, Bird SJ. Critical illness myopathy. Muscle Nerve 2000; 23: 1785-8; http://dx.doi.org/10.1002/1097-4598(200012)23:12<1785::AID-MUS1>3.0.CO;2-J

50. Tzanis G, Vasileiadis I, Zervakis D, et al. Maximum inspiratory pressure, a surrogate parameter for the assessment of ICU-acquired weakness. BMC Anesthesiol 2011; 11: 14; http://dx.doi. org/10.1186/1471-2253-11-14

51. Rich MM, Teener JW, Raps EC, et al. Muscle is electrically inexcitable in acute quadriplegic myopathy. Neurology 1996; 46: 731-6; http://dx.doi.org/10.1212/WNL.46.3.731

52. Trojaborg W, Weimer LH, Hays AP. Electrophysiologic studies in critical illness associated weakness: myopathy or neuropathy - a reappraisal. Clin Neurophysiol 2001; 112: 1586-93; http:// dx.doi.org/10.1016/S1388-2457(01)00572-7

53. Grimm A, Decard BF, Axer H, et al. The Ultrasound pattern sum score - UPSS. A new method to differentiate acute and subacute neuropathies using ultrasound of the peripheral nerves. Clin Neurophysiol 2015 [In Press]; http://dx.doi.org/10.1016/j.clinph.2015.01.011

54. Grimm A, Teschner U, Porzelius C, et al. Muscle ultrasound for early assessment of critical illness neuromyopathy in severe sepsis. Crit Care 2013; 17: R227; http://dx.doi.org/10.1186/cc13050

55. De Letter MA, van Doorn PA, Savelkoul HF, et al. Critical illness polyneuropathy and myopathy (CIPNM): evidence for local immune activation by cytokine-expression in the muscle tissue. $J$ Neuroimmunol 2000; 106: 206-13; http://dx.doi.org/10.1016/S0165-5728(99)00252-0

56. Fan E, Cheek F, Chlan L, et al. An official American Thoracic Society Clinical Practice guideline: the diagnosis of intensive care unit-acquired weakness in adults. Am J Respir Crit Care Med 2014; 190: 1437-46; http://dx.doi.org/10.1164/rccm.201411-2011ST

57. Lacomis D, Petrella JT, Giuliani MJ. Causes of neuromuscular weakness in the intensive care unit: a study of ninety-two patients. Muscle Nerve 1998; 21: 610-7; http://dx.doi.org/10.1002/(SICI)10974598(199805)21:5<610::AID-MUS7>3.0.CO;2-B

58. Mozaffar T. Critical illness myopathy. Muscle Nerve 2001; 24: 973-4; http://dx.doi.org/10.1002/ mus.1098.abs

59. Bierbrauer J, Koch S, Olbricht C, et al. Early type II fiber atrophy in intensive care unit patients with nonexcitable muscle membrane. Crit Care Med 2012; 40: 647-50; http://dx.doi.org/10.1097/ CCM.0b013e31823295e6

60. Witteveen E, Wieske L, Verhamme C, et al. Muscle and nerve inflammation in intensive care unit-acquired weakness: a systematic translational review. J Neurol Sci 2014; 345: 15-25; http:// dx.doi.org/10.1016/j.jns.2014.07.014

61. Stibler H, Edstrom L, Ahlbeck K, et al. Electrophoretic determination of the myosin/actin ratio in the diagnosis of critical illness myopathy. Intensive Care Med 2003; 29: 1515-27; http://dx.doi. org/10.1007/s00134-003-1894-9

62. Kress JP, Pohlman AS, O'Connor MF, et al. Daily interruption of sedative infusions in critically ill patients undergoing mechanical ventilation. $N$ Engl J Med 2000; 342: 1471-7; http://dx.doi. org/10.1056/NEJM200005183422002

63. Rich MM, Pinter MJ. Crucial role of sodium channel fast inactivation in muscle fibre inexcitability in a rat model of critical illness myopathy. J Physiol 2003; 547: 555-66; http://dx.doi.org/10.1113/ jphysiol.2002.035188

64. Rich MM, McGarvey ML, Teener JW, et al. ECG changes during septic shock. Cardiology 2002; 97: 187-96; http://dx.doi.org/10.1159/000063120

65. Spitzer AR, Giancarlo T, Maher L, et al. Neuromuscular causes of prolonged ventilator dependency. Muscle Nerve 1992; 15: 682-6; http://dx.doi.org/10.1002/mus.880150609

66. al-Lozi MT, Pestronk A, Yee WC, et al. Rapidly evolving myopathy with myosin-deficient muscle fibers. Ann Neurol 1994; 35: 273-9; http://dx.doi.org/10.1002/ana.410350306 
67. Zochodne DW, Ramsay DA, Saly V, et al. Acute necrotizing myopathy of intensive care: electrophysiological studies. Muscle Nerve 1994; 17: 285-92; http://dx.doi.org/10.1002/ mus.880170305

68. Fenzi F, Latronico N, Refatti N, et al. Enhanced expression of E-selectin on the vascular endothelium of peripheral nerve in critically ill patients with neuromuscular disorders. Acta Neuropathol 2003; 106: $75-82$

69. Weber-Carstens S, Schneider J, Wollersheim T, et al. Critical illness myopathy and GLUT4: significance of insulin and muscle contraction. Am J Respir Crit Care Med 2013; 187: 387-96; http://dx.doi.org/10.1164/rccm.201209-1649OC

70. Helliwell TR, Wilkinson A, Griffiths RD, et al. Muscle fibre atrophy in critically ill patients is associated with the loss of myosin filaments and the presence of lysosomal enzymes and ubiquitin. Neuropathol Appl Neurobiol 1998; 24: 507-17; http://dx.doi.org/10.1046/j.1365-2990.1998.00144.x

71. Minetti C, Hirano M, Morreale G, et al. Ubiquitin expression in acute steroid myopathy with loss of myosin thick filaments. Muscle Nerve 1996; 19: 94-6; http://dx.doi.org/10.1002/(SICI)10974598(199601)19:1\%3C94::AID-MUS14\%3E3.0.CO;2-3

72. Langhans C, Weber-Carstens S, Schmidt F, et al. Inflammation-induced acute phase response in skeletal muscle and critical illness myopathy. PLoS One 2014; 9: e92048; http://dx.doi.org/10.1371/ journal.pone.0092048

73. Di Giovanni S, Molon A, Broccolini A, et al. Constitutive activation of MAPK cascade in acute quadriplegic myopathy. Ann Neurol 2004; 55: 195-206; http://dx.doi.org/10.1002/ana.10811

74. Hotchkiss RS, Swanson PE, Freeman BD, et al. Apoptotic cell death in patients with sepsis, shock, and multiple organ dysfunction. Crit Care Med 1999; 27: 1230-51; http://dx.doi. org/10.1097/00003246-199907000-00002

75. Montejo Gonzalez JC. Contribution of nutritional support to treatment neuromuscular impairmets of critically ill patients. Nutr Hosp 2006; 21: 118-22

76. Yuki N, Hartung HP. Guillain-Barre syndrome. N Engl J Med 2012; 366: 2294-304; http://dx.doi. org/10.1056/NEJMra1114525

77. Burnham EL, Moss M, Ziegler TR. Myopathies in critical illness: characterization and nutritional aspects. J Nutr 2005; 135: 1818S-23S

78. Johnson KL. Neuromuscular complications in the intensive care unit: critical illness polyneuromyopathy. AACN Adv Crit Care 2007; 18: 167-80; http://dx.doi.org/10.1097/01. AACN.0000269260.99169.70

79. Weiss-Guillet EM, Takala J, Jakob SM. Diagnosis and management of electrolyte emergencies. Best Pract Res Clin Endocrinol Metab 2003; 17: 623-51; http://dx.doi.org/10.1016/S1521690X(03)00056-3

80. Hiromatsu K, Kobayashi T, Fujii N, et al. Hypernatremic myopathy. J Neurol Sci 1994; 122: 144-7; http://dx.doi.org/10.1016/0022-510X(94)90291-7

81. Argov Z, Latronico N. Neuromuscular complications in intensive care patients. Handb Clin Neurol 2014; 121: 1673-85; http://dx.doi.org/10.1016/B978-0-7020-4088-7.00108-5

82. Wong JM. Propofol infusion syndrome. Am J Ther 2010; 17: 487-91; http://dx.doi.org/10.1097/ MJT.0b013e3181ed837a

83. Azzarelli B, Roessmann U. Diffuse "anoxic" myelopathy. Neurology 1977; 27: 1049-52; http:// dx.doi.org/10.1212/WNL.27.11.1049

84. Khan J, Harrison TB, Rich MM, et a. Early development of critical illness myopathy and neuropathy in patients with severe sepsis. Neurology 2006; 67: 1421-5; http://dx.doi.org/10.1212/01. wnl.0000239826.63523.8e

85. Lowry SF. Sepsis and its complications: clinical definitions and therapeutic prospects. Crit Care Med 1994; 22: S1-2 
86. Dhainaut JF, Tenaillon A, Le Tulzo Y, et al. Platelet-activating factor receptor antagonist BN 52021 in the treatment of severe sepsis: a randomized, double-blind, placebo-controlled, multicenter clinical trial. BN 52021 Sepsis Study Group. Crit Care Med 1994; 22: 1720-8; http://dx.doi. org/10.1097/00003246-199422110-00005

87. Spies CD, Reinhart K, Witt I, et al. Influence of N-acetylcysteine on indirect indicators of tissue oxygenation in septic shock patients: results from a prospective, randomized, double-blind study. Crit Care Med 1994; 22: 1738-46; http://dx.doi.org/10.1097/00003246-199411000-00007

88. Wijdicks EF, Fulgham JR. Failure of high dose intravenous immunoglobulins to alter the clinical course of critical illness polyneuropathy. Muscle Nerve 1994; 17: 1494-5

89. Brunner R, Rinner W, Haberler C, et al. Early treatment with IgM-enriched intravenous immunoglobulin does not mitigate critical illness polyneuropathy and/or myopathy in patients with multiple organ failure and SIRS/sepsis: a prospective, randomized, placebo-controlled, double-blinded trial. Crit Care 2013; 17: R213; http://dx.doi.org/10.1186/cc13028

90. Needham DM, Wozniak AW, Hough CL, et al. Risk factors for physical impairment after acute lung injury in a national, multicenter study. Am J Respir Crit Care Med 2014; 189: 1214-24; http:// dx.doi.org/10.1164/rccm.201401-0158OC

91. Hermans G, De Jonghe B, Bruyninckx F, et al. Interventions for preventing critical illness polyneuropathy and critical illness myopathy. Cochrane Database Syst Rev 2014; 1: CD006832

92. Fan E, Dowdy DW, Colantuoni E, et al. Physical complications in acute lung injury survivors: a two-year longitudinal prospective study. Crit Care Med 2014; 42: 849-59; http://dx.doi.org/10.1097/ CCM.0000000000000040

93. Brook AD, Ahrens TS, Schaiff R, et al. Effect of a nursing-implemented sedation protocol on the duration of mechanical ventilation. Crit Care Med 1999; 27: 2609-15; http://dx.doi. org/10.1097/00003246-199912000-00001

94. De Jonghe B, Cook D, Griffith L, et al. Adaptation to the Intensive Care Environment (ATICE): development and validation of a new sedation assessment instrument. Crit Care Med 2003; 31: 2344-54; http://dx.doi.org/10.1097/01.CCM.0000084850.16444.94

95. Needham DM, Korupolu R, Zanni JM, et al. Early physical medicine and rehabilitation for patients with acute respiratory failure: a quality improvement project. Arch Phys Med Rehabil 2010; 91: 536-42; http://dx.doi.org/10.1016/j.apmr.2010.01.002

96. Godoy DA, Di Napoli M, Rabinstein AA. Treating hyperglycemia in neurocritical patients: benefits and perils. Neurocrit Care 2010; 13: 425-38; http://dx.doi.org/10.1007/s12028-010-9404-8

97. van den Berghe $\mathrm{G}$, Wouters $\mathrm{P}$, Weekers $\mathrm{F}$, et al. Intensive insulin therapy in critically ill patients. $N$ Engl J Med 2001; 345: 1359-67; http://dx.doi.org/10.1056/NEJMoa011300

98. Finfer S, Liu B, Chittock DR, et al. Hypoglycemia and risk of death in critically ill patients. $N$ Engl J Med 2012; 367: 1108-18; http://dx.doi.org/10.1056/NEJMoa1204942

99. Weber-Carstens S, Deja M, Koch S, et al. Risk factors in critical illness myopathy during the early course of critical illness: a prospective observational study. Crit Care 2010; 14: R119; http://dx.doi. org/10.1186/cc9074

100. Hermans G, Schrooten M, Van Damme P, et al. Benefits of intensive insulin therapy on neuromuscular complications in routine daily critical care practice: a retrospective study. Crit Care. 2009; 13(1): R5

101. American Diabetes Association. Executive summary: Standards of medical care in diabetes 2012. Diabetes Care 2012; 35: S4-S10; http://dx.doi.org/10.2337/dc12-s004

102. Routsi C, Gerovasili V, Vasileiadis I, et al. Electrical muscle stimulation prevents critical illness polyneuromyopathy: a randomized parallel intervention trial. Crit Care 2010; 14: R74 
103. Burke D, Gorman E, Stokes D, et al. An evaluation of neuromuscular electrical stimulation in critical care using the ICF framework: a systematic review and meta-analysis. Clin Respir J 2014 [Epub ahead of print]; http://dx.doi.org/10.1111/crj.12234

104. Leijten FS, de Weerd AW. Critical illness polyneuropathy. A review of the literature, definition and pathophysiology. Clin Neurol Neurosurg 1994; 96: 10-9; http://dx.doi.org/10.1016/03038467(94)90023-X

105. Nagaratnam N, Jamieson G, Chiu K, et al. Critical illness neuropathy. Neurorehabil Neural Repair 2001; 15: 81-4; http://dx.doi.org/10.1177/154596830101500111

106. Koch S, Wollersheim T, Bierbrauer J, et al. Long-term recovery In critical illness myopathy is complete, contrary to polyneuropathy. Muscle Nerve 2014; 50: 431-6; http://dx.doi.org/10.1002/ mus. 24175

107. Williams S, Horrocks IA, Ouvrier RA, et al. Critical illness polyneuropathy and myopathy in pediatric intensive care: A review. Pediatr Crit Care Med 2007; 8: 18-22; http://dx.doi. org/10.1097/01.pcc.0000256623.01254.40

108. Kerbaul F, Brousse M, Collart F, et al. Combination of histopathological and electromyographic patterns can help to evaluate functional outcome of critical ill patients with neuromuscular weakness syndromes. Crit Care 2004; 8: R358-66; http://dx.doi.org/10.1186/cc2925

109. Bednarik J, Vondracek P, Dusek L, et al. Risk factors for critical illness polyneuromyopathy. J Neurol 2005; 252: 343-51; http://dx.doi.org/10.1007/s00415-005-0654-x 